\title{
OPTICAL SPECIFICATION OF LIGHT-SCATTERING MATERIALS
}

\author{
By Deane B. Judd
}

(With the collaboration of W. N. Harrison, B. J. Sweo, E. F. Hickson, A. J. Eickhoff, Merle B. Shaw, and George C. Paffenbarger)

\section{ABSTRACT}

In 1931 Kubelka and Munk worked out the relationship between reflectance and thickness of material for thin, homogeneous layers illuminated diffusely. In the equation expressing this relationship, the hypothetical ideal material is defined by two constants, reflectivity and coefficient of scatter. In the present paper are given data demonstrating how well several materials of commerce can be specified by these constants. These include data on vitreous enamel, dental silicate cement, cold-water paint, and paper.

\section{CONTENTS}

I. Introduction

II. Definition of terms

III. Apparatus and method_._. 289

1. General method .......... 289

2. Graphical aids

3. Conditions of measurement__._. 292

IV. Preparation of samples: Results and discussion

1. Vitreous enamels (by W. N. Harrison and B. J. Sweo) $\ldots . . .295$

(a) Contrast-ratio method .................... 297

(b) Reflectivity method_................... 298

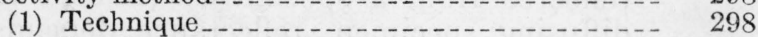

(2) Results

(3) Significance of results ........ 300

(c) Dual-thickness method _._. 301

(d) Discussion _... 302

2. Cold-water paints (by E. F. Hickson and A. J. Eickhoff) -... 302

(a) Preparation of samples_................. 303

(b) Measurements of apparent reflectance $\ldots . . . \ldots 303$

(c) Reduction of data

(d) Discussion _........ 305

3. Paper (by Deane B. Judd and Merle B. Shaw) 306

(a) Preparation of samples_....... 307

(1) Writing papers

(2) Book paper......... 309

(3) Newsprint paper

(b) Measurements

(c) Reduction of data.... 310

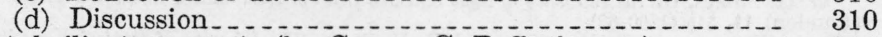

4. Dental silicate cements (by George C. Paffenbarger)

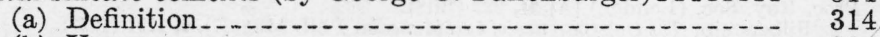

(b) Use .

(c) Preparation of specimens

(d) Method of measurement.............. 314

(e) Discussion of data

V. Summary $\ldots \ldots \ldots \ldots$ 


\section{INTRODUCTION}

Relations between the incident, reflected, and emergent light from a thin, homogeneous layer of absorbing and scattering material have been worked out in various forms. ${ }^{1}$ Usually these relations have been developed in theory by considering perfectly diffused light incident on any elementary layer of the material which is assumed to absorb a portion, reflect diffusely another portion, and transmit diffusely the remainder. Traveling of the diffused light through the thin sheet of material has been considered, but scattering of light to the sides, or light lost through the edges of the material, has usually been left out of account because of the added complexity. Of the various derivations the most readily applicable to practical measurement is that of Kubelka and Munk, who carried through the derivation in such a way that the related quantities are those which are customarily measured. The equations of this important derivation have been reproduced and the discussion of them given in English by Steele. ${ }^{2}$

Measurements on materials result in values of reflectance which are related to thickness in a way somewhat different from that described by the Kubelka-Munk formula; first, because real materials differ from the ideal material assumed in the derivation by being inhomogeneous; second, because the reflectometers fail either to diffuse perfectly the light falling on the sample or to measure all light diffusely reflected, or both; third, because some light is lost through the edges of the samples; and, fourth, because the amounts of light absorbed and scattered by the materials vary according to the wave length of the light. The purpose of the present paper is to discover how large are the departures from theory due to these sources and to inquire whether a description of materials in terms of the simple KubelkaMunk formulation is sufficiently exact to be of value.

\section{DEFINITION OF TERMS}

$R \equiv$ light reflectance of a specimen, or the fraction of incident light reflected from a specimen. (Except for the ideal, perfectly diffusing specimen, reflectance depends on the angular distribution of incident light.)

$A \equiv$ apparent light reflectance of a specimen, or the reflectance which an ideal, perfectly diffusing specimen would require in order to have the same brightness as the actual specimen under the same illuminating and viewing conditions. (In this work the illuminating and viewing conditions are chosen so as to avoid taking into account light specularly reflected from glossy specimens; the apparent light reflectance so taken has sometimes been called the diffuse reflectance.)

$R_{\infty} \equiv$ light reflectivity of the material, or the reflectance of an infinitely thick specimen of the material; that is, practically,

${ }_{1}^{1}$ G. G. Stokes, On the intensity of light reflected from or transmitted through a pile of plates, Proc. Roy. Soc. (London) 11, 545 (1860-62).

H. J. Channon, F. F. Renwick, and B. V. Storr, The behavior of scattering media in fully diffused light, Proc. Roy. Soc. (London) [A] 94, 222 (1918).

L. Silberstein, The transparency of turbid media, Phil. Mag. [7], 4, 1291 (1927).

M. Gurevich, Ueber eine rationelle Klassification der lichtstreuenden Medien, Physik. Z. 31, 753 (1930).

J. W. Ryde and B. S. Cooper, The scattering of light by turbid media, Proc. Roy. Soc. (London) [A], 131, 451 (1931).

P. Kubelka and F. Munk, Ein Beitrag zur Optik der Farbanstriche, Z. tech. Phys. 12, 593 (1931).

T. Smith, The hiding power of diffusing media, Trans. Opt. Soc. 33, 150 (1231-32).

${ }_{2}$ F. A. Steele, The optical characteristics of paper. I. The mathematical relationships between basis weight, reflectance, contrast ratio and other optical properties, Paper Trade J. 100, no. 12, 37 (Mar. 21, 1935). 
one so thick that a further increase in thickness does not change its reflectance.

$A_{\infty} \equiv$ apparent light reflectivity of the material.

$R_{0} \equiv$ light reflectance of a specimen in contact with a backing of zero reflectance.

$R_{1} \equiv$ light reflectance of a specimen in contact with a backing of unit (100 percent) reflectance.

$R_{R^{\prime}} \equiv$ light reflectance of a specimen in contact with a backing of reflectance, $R^{\prime}\left(0 \leq R^{\prime} \leq 1\right)$.

$A_{0}, A_{1}$, and $\mathrm{A}_{R^{\prime}}$ refer to apparent light reflectances and are analogous to $R_{0}, R_{1}$, and $R_{R^{\prime}}$, respectively.

$C \equiv \mathrm{R}_{0} / R_{1} \doteq A_{0} / A_{1}$, called ideal contrast ratio.

$C_{0.89} \equiv A_{0} / \bar{A}_{0.89}$, called TAPPI opacity ${ }^{3}$ provided the illumination be in effect perfectly diffused and the direction of view not more than $20^{\circ}$ from normal.

$C_{R^{\prime}} \equiv R_{0} / R_{R^{\prime}} \doteq A_{0} / A_{R^{\prime}}$, called simply contrast ratio.

$C_{\infty} \equiv A_{0} / A_{\infty} \doteq R_{0} / R_{\infty}$, called printing opacity if the material is paper.

$P \equiv C_{0.80}$ for an enamel coating of $6.0 \mathrm{~g} / \mathrm{dm}^{2}$, called covering power of a vitreous enamel.

$X \equiv$ thickness of the specimen (sometimes measured by weight per unit area, as in vitreous enamels, paint films, and paper; sometimes by volume per unit area, as in paste for cold-water paint.)

$S \equiv\left(d R_{0} / d X\right)_{X \rightarrow 0}$, called coefficient of scatter, the rate of increase of reflectance of a specimen with thickness for nearly zero thickness of specimen over a black backing.

$S X \equiv$ scattering power of a particular specimen consisting of a thickness, $X$, of material having coefficient of scatter, $S$.

\section{APPARATUS AND METHOD}

\section{GENERAL METHOD}

Attention has been confined in this paper chiefly to materials whose reflectance is fairly high and nearly nonselective with respect to wave length. These materials (whites and near-whites) may be expected to have reflectivities and coefficients of scatter nearly independent of the wave length of incident light and there is hope that single average values of reflectivity and coefficient of scatter may be found to represent them properly even when illuminated by light (such as daylight) of a considerable wave-length range. It is not to be expected that materials having highly chromatic colors can be so represented; such materials will require for their specification values of reflectivity and coefficient of scatter as functions of wave length.

Data on four classes of materials are reported in this paper. The general plan of the investigation for each class of materials is:

1. Select a number ( 3 to 5 ) of representative materials ranging in reflectivity from the highest to the lowest usual values.

2. Prepare from each material a number of specimens ranging in thickness from the thinnest usually encountered in practice up nearly to that of an opaque layer.

3. Measure apparent light reflectance for black backing, $A_{0}$, and for white backing, $A_{R^{\prime}}$, where $R^{\prime}$, the reflectance of the backing, is between 0.70 and 0.90 .

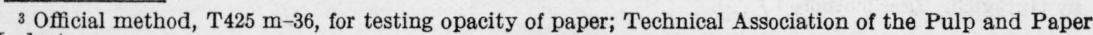
Industry. 
4. Check these experimental values, $\left(A_{0}, A_{R^{\prime}}\right)$ against the KubelkaMunk formula on the assumption that $A_{0}$ and $A_{R^{\prime}}$ are adequate approximations to $R_{0}$ and $R_{k^{\prime}}$, respectively.

\section{GRAPHICAL AIDS}

A number of graphical aids for this comparison have been prepared and will now be described.

The Kubelka-Munk formula is

$$
R_{R^{\prime}}=\frac{\left(R^{\prime}-R_{\infty}\right) / R_{\infty}-R_{\infty}\left(R^{\prime}-1 / R_{\infty}\right) e^{S X\left(1 / R_{\infty}-R_{\infty}\right)}}{\left(R^{\prime}-R_{\infty}\right)-\left(R^{\prime}-1 / R_{\infty}\right) e^{S X\left(1 / R_{\infty}-R_{\infty}\right)}}
$$

From two measurements of reflectance, $R_{R^{\prime}}$, of a specimen of known thickness, $X$, one for each of two backings of different reflectance, $R^{\prime}$, it is possible to solve for $R_{\infty}$ and $S$ from equation 1 and so obtain a specification of the material. This can also be done from two measurements of reflectance made with the same backing but with samples of different thickness, $X$. The form of equation 1 is so little adapted, however, to easy solution of pairs of simultaneous equations of this sort that all of the solutions required for reducing the experimental data of the present study have been worked out in advance and expressed graphically on reflectance-opacity charts by families of curves for different values of $S X$ and $R_{\infty}$. The ordinate of these charts is reflectance, $R_{0}$, for black backing, the abscissa is contrast ratio, $C_{R^{\prime}}$. Figure 1 is a reflectance-opacity chart in which the abscissa is $\mathrm{C}_{0.89}$ or TAPPI opacity. ${ }^{4}$ Figure 2 is a reflectanceopacity chart in which the abscissa is $C_{0.80}$. Figure 3 is a chart in which the abscissa is $C_{0.70}$. The curves having positive slopes represent the increase in reflectance and opacity of specimens made of increasing thicknesses of the same ideal material. The highest reflectance is obtained, of course, for specimens so thick that they are opaque $\left(C_{R^{\prime}}=1.00\right)$, and this maximum reflectance is the reflectivity, $R_{\infty}$. The relative thicknesses of the specimens are indicated by the intersections with the curves having negative slopes. Each of the latter curves represents ideal specimens of constant scattering power, $S X$; each such curve shows the decrease in reflectance, $R_{0}$, for black backing and the increase in opacity, $C_{R^{\prime}}$, of such specimens as their reflectivities are lowered as, for example, by admixture of a nonscattering, light-absorbing material like black dye or black pigment.

These charts ${ }^{5}$ provide solutions for the two constants $R_{\infty}$ and $S$, of the ideal material from thickness of sample and given values of measurable reflectances, $R_{0}$ and $R_{R^{\prime}}$. Or, if $R_{\infty}$ is determined by direct reflectance measurement of a thick layer, the charts yield scattering coefficient, $S$, from thickness of sample, $X$, and reflectance, $R_{0}$. In the present work, these relations were investigated by means of values of $A_{0}, A_{\infty}$, and $A_{R^{\prime}}$, the analogues of $R_{0}, R_{\infty}$, and $R_{R^{\prime}}$. Figure 1 is particularly applicable to measurements of paper because its abscissa is $C_{0.89}$, the particular contrast ratio identified with opacity according to the test methods of the Technical Association of the

\footnotetext{
D. B. Judd, The dependence of reflectance and opacity on thickness; Relation between contrast ratio and printing opacity, Paper Trade J. 101, no. 5, TS 40 (August 1, 1935).

A chart serving similar purposes, but having transmission as abscissa instead of opacity, was worked out by Gurevich. (See footnote 1.)
} 


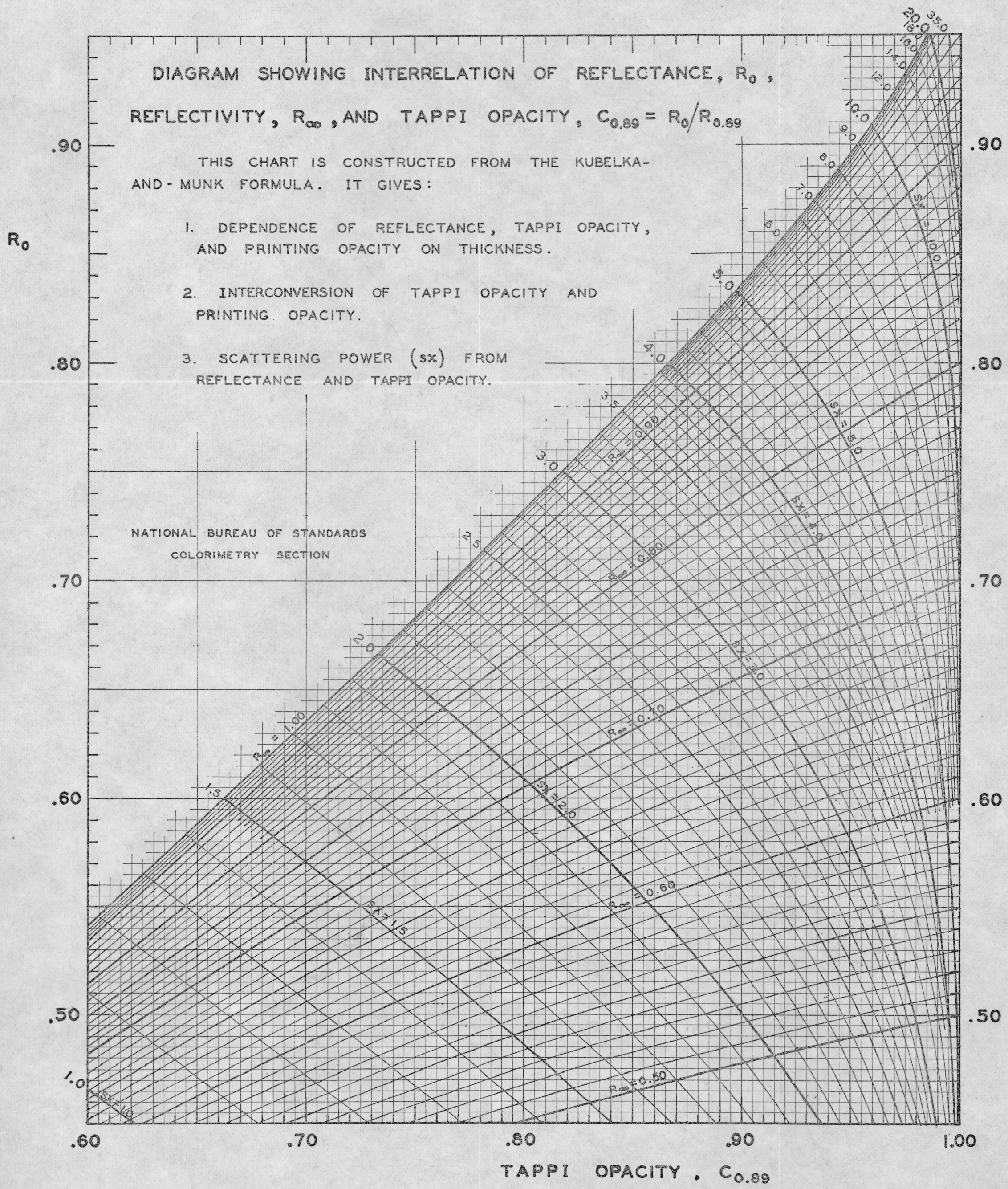

To be used in specification of paper.

Figure 1.-Reflectance-opacity chart for white backing of reflectance, $R^{\prime}=0.89$.

7187--37 (Face p. 290, RP1026) No. 1 


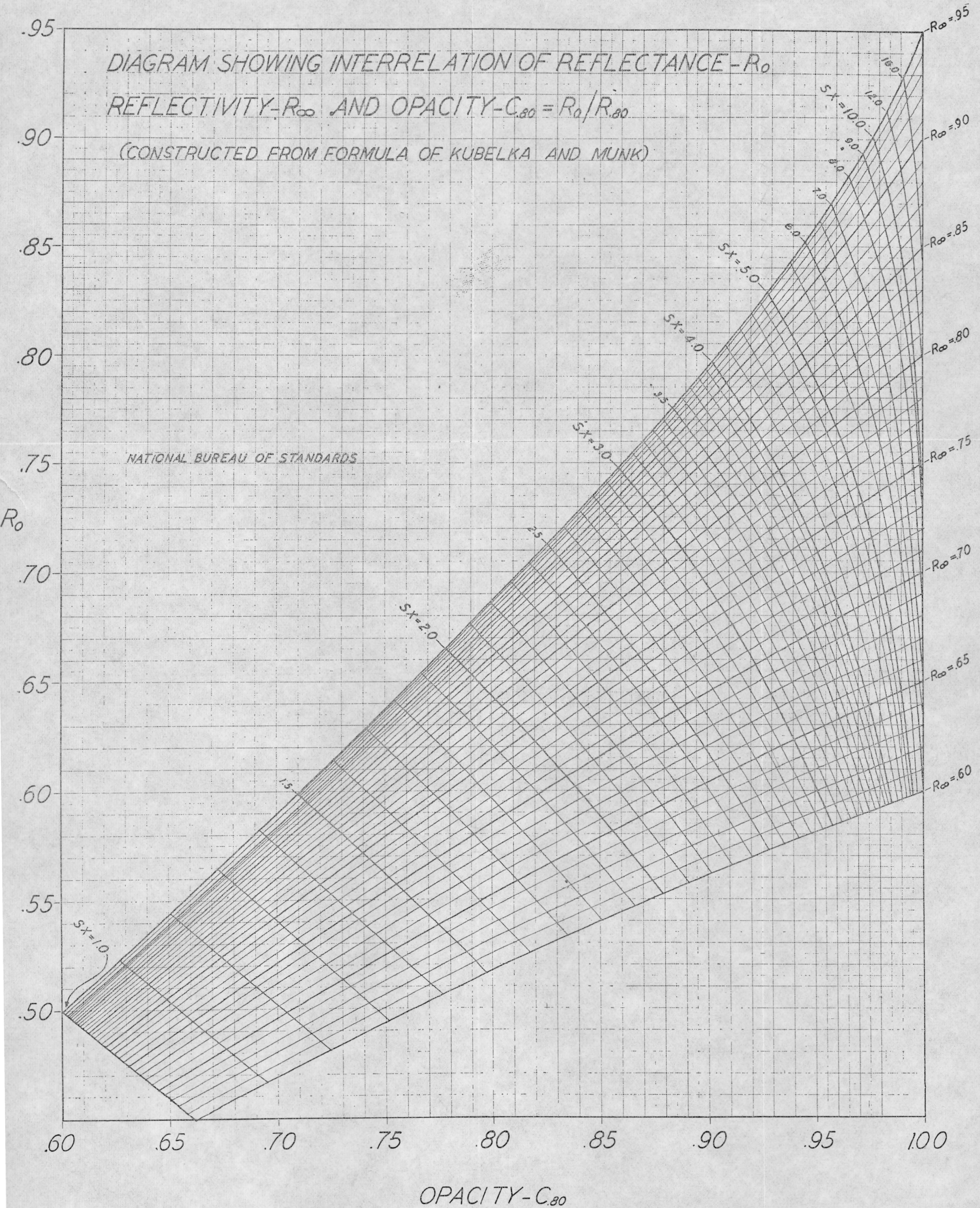

FigURE 2.-Reflectance-opacity chart for white backing of reflectance, $R^{\prime}=0.80$. 


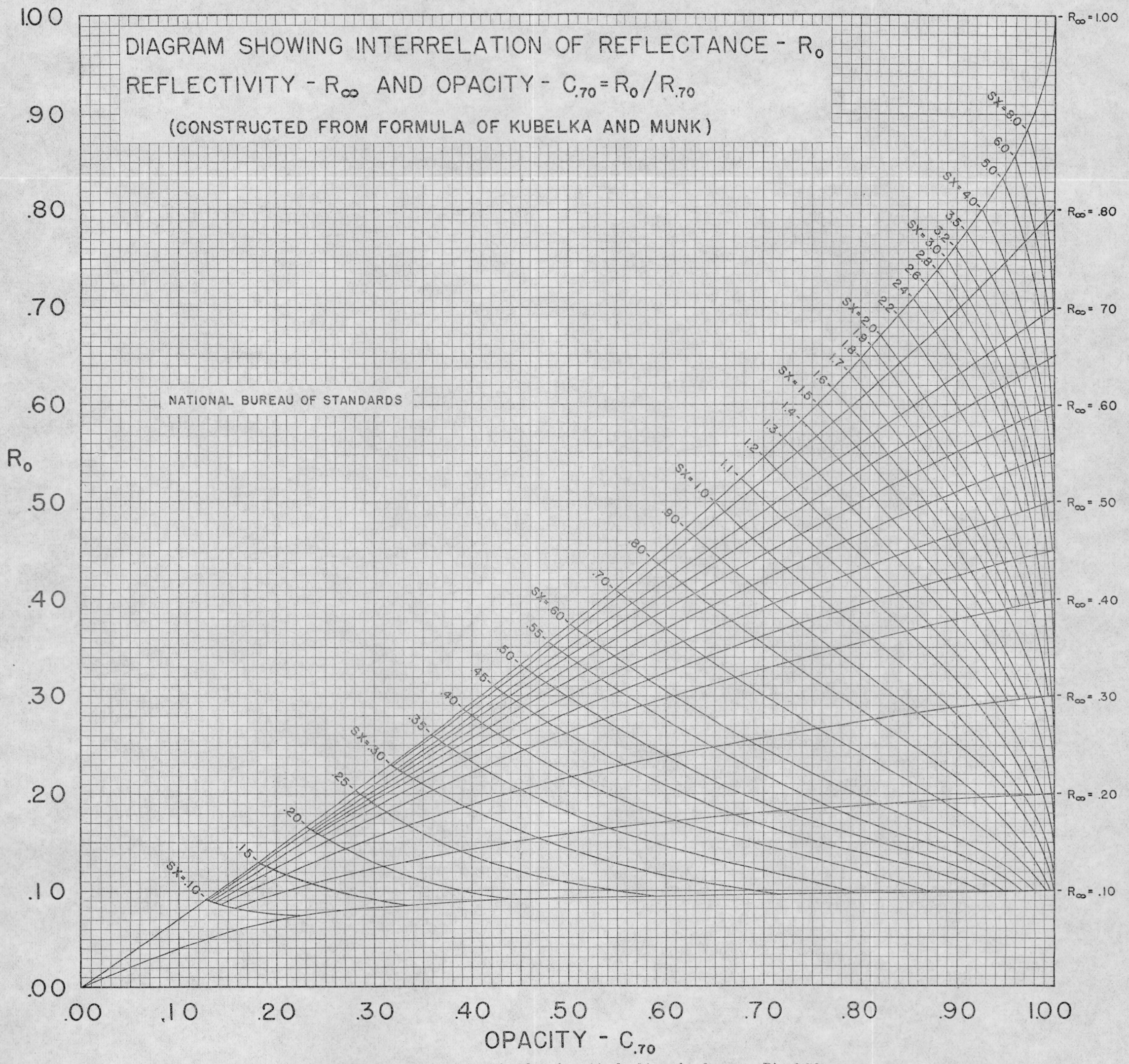

FIGURE 3.-Reflectance-oprcity chart for white backing of reflectance, $R^{\prime}=0.70$. 
Pulp and Paper Industry. ${ }^{6}$ Figure 2 refers more particularly to vitreous enamels and paint films because it is more feasible to use as the white backings in such cases coatings which have a reflectance of about 0.80 . Figure 3 is used here for dental silicate cements because white backings having reflectances of about 0.70 were found to be convenient for this material.

In many cases, it was found that the white backing did not exactly equal either $0.70,0.80$, or 0.89 , so none of the charts could be used directly. In such cases use was made of a formula connecting contrast ratio, $C_{R^{\prime}}$ with $R^{\prime}, R_{0}$, and ideal contrast ratio, $C .^{7}$ This formula is also based on the assumption that the illumination of the specimen is perfectly diffused, but applies to nonhomogeneous as well as homogeneous specimens. It is particularly convenient in the reduction of various kinds of data because $R^{\prime}, C$, and $C_{R^{\prime}}$ may each be found explicitly, thus:

$$
\begin{gathered}
C_{R^{\prime}}=\frac{C\left(1-R^{\prime} R_{0}\right)}{C\left(1-R^{\prime}\right)+R^{\prime}\left(1-R_{0}\right)} \\
C=\frac{R^{\prime} C_{R^{\prime}}\left(1-R_{0}\right)}{1+R^{\prime} C_{R^{\prime}}-C_{R^{\prime}}-R^{\prime} R_{0}} \\
R^{\prime}=\frac{C\left(1-C_{R^{\prime}}\right)}{C_{R^{\prime}}(1-C)+R_{0}\left(C-C_{R^{\prime}}\right)}
\end{gathered}
$$

By substituting equation $2 \mathrm{~b}$ in equation $2 \mathrm{a}$, an expression for $C_{R^{\prime}}$ may be found for any desired value of $R^{\prime}$, say 0.89 , provided $R_{0}$ and $C_{R^{\prime}}$ for any other value of $R^{\prime}$ be known. This expression is written for $R^{\prime}=0.89, R^{\prime}=0.80$, and $R^{\prime}=0.70$, respectively:

$$
\begin{aligned}
& C_{0.89}=\frac{1-0.89 R_{0}}{0.11+\frac{0.89\left(1-R^{\prime} R_{0}-C_{R^{\prime}}+R^{\prime} C_{R^{\prime}}\right)}{R^{\prime} C_{R^{\prime}}}} \\
& C_{0.80}=\frac{1-0.80 R_{0}}{0.20+\frac{0.80\left(1-R^{\prime} R_{0}-C_{R^{\prime}}+R^{\prime} C_{R^{\prime}}\right)}{R^{\prime} C_{R^{\prime}}}} \\
& C_{0.70}=\frac{1-0.70 R_{0}}{0.30+\frac{0.70\left(1-R^{\prime} R_{0}-C_{R^{\prime}}+R^{\prime} C_{R^{\prime}}\right)}{R^{\prime} C_{R^{\prime}}}}
\end{aligned}
$$

If $R_{0}$ and $C_{R^{\prime}}\left(R^{\prime} \neq 0.89\right)$ be measured for a given specimen and it be desired to use figure 1 for finding the constants $R_{\infty}$ and $S$ of the material of this specimen, equation 3a may be used. If it be desired to use fig. 2 or 3 for finding the constants of the material, equation $3 \mathrm{~b}$ or $3 \mathrm{c}$, respectively, may be used. Figure 4 is based on equation $3 \mathrm{~b}$ and shows how the correction, $C_{R^{\prime}}-C_{0.80}$, varies with $R^{\prime}-0.80$ for different values of $C_{0.80}$ and $R_{0}$. Note that the correction in every case is so nearly proportional to $R^{\prime}-0.80$ that for deviations of $R^{\prime}$ from 0.80 equal to 0.01 no significant errors (errors greater than 0.002 ) will occur if the correction is computed as one-tenth of that for

\footnotetext{
${ }^{6}$ See footnote 3. The apparent reflectance of white backing mentioned in the standard method is 0.915 relative to that for magnesium oxide. Since the reflectance of magnesium oxide for diffuse illumination is

about 0.97 , this corresponds to $R^{\prime}=0.915 \times 0.97=0.89$.
7 D. B. Judd, Opacity standards, J. Research NBS 13, 281 (1934) RP709; Paper Trade J. 100, no. 1, TS 28 (1935).
} 
$\left|R^{\prime}-0.80\right|=0.10$. Figures 5 and 6 were computed from equations $3 \mathrm{~b}$ and $3 \mathrm{c}$, respectively, and, by virtue of the near proportionality between correction and deviation of $R^{\prime}$ from the plotted value $(0.89$, 0.80 , or 0.70 ), as in figure 4 , figures 5 and 6 serve the purposes of equations $3 \mathrm{a}, 3 \mathrm{~b}$, and $3 \mathrm{c}$ for most cases arising in practice. The dotted curves (constant $R_{\infty}$ ) on these figures were found by reference

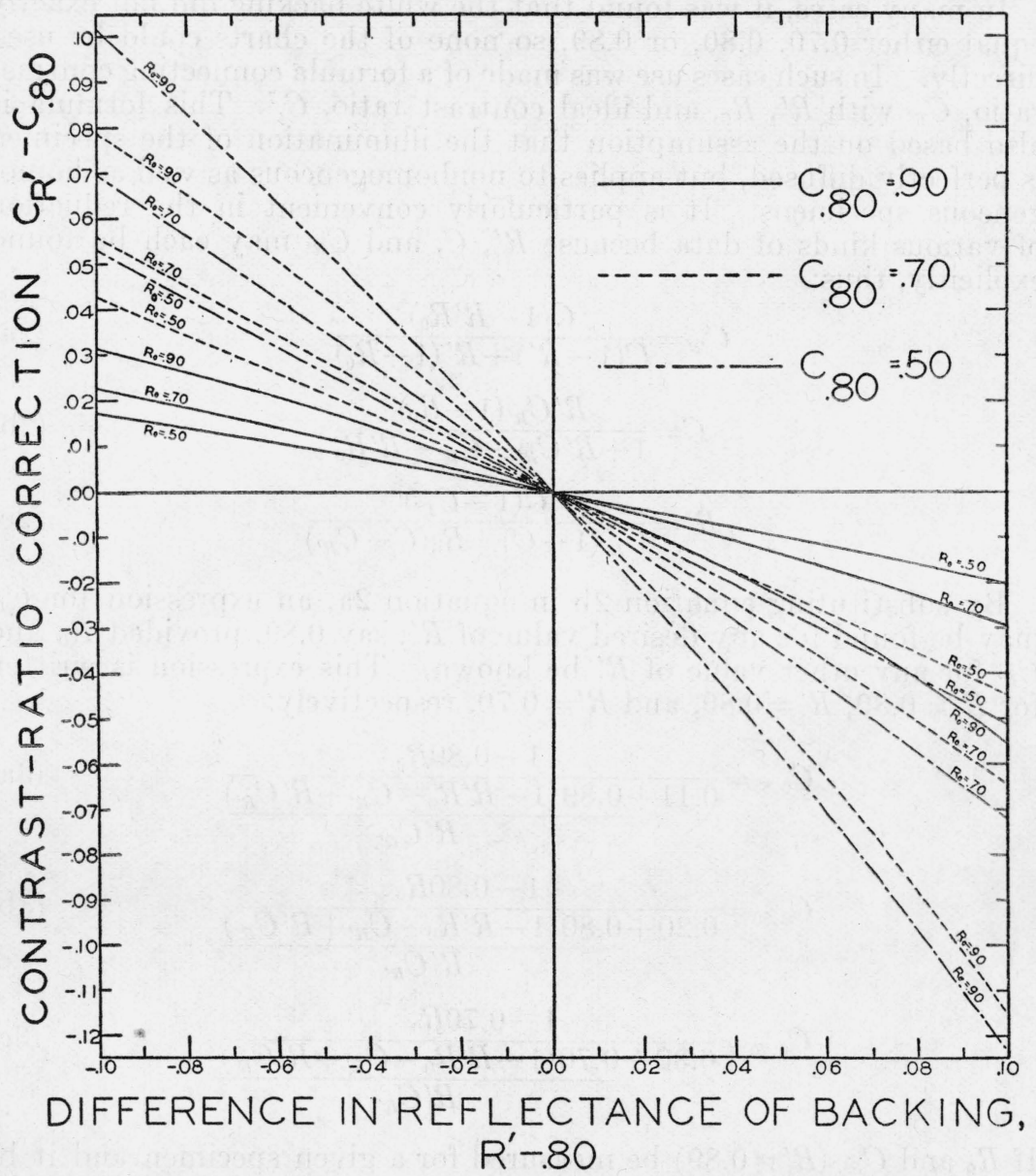

FIGURE 4.-Demonstration that the correction to contrast-ratio is nearly proportional to change in reflectance of white backing, $R^{\prime}$.

to the respective reflectance-opacity charts (figs. 1, 2, and 3), and are often more convenient for obtaining interpolated values than the solid curves (constant $R_{0}$ ).

\section{CONDITIONS OF MEASUREMENT}

The general plan in this investigation has been to use the reflectometers customarily applied to the materials investigated, and to use them in the customary ways. Some of the usual methods, however, are such that no close check on the Kubelka-Munk formula is to be expected, and such methods have been avoided. It is convenient in 
the discussion of these methods to classify the materials investigated as (1) those in which the scattering elements are distributed in air as
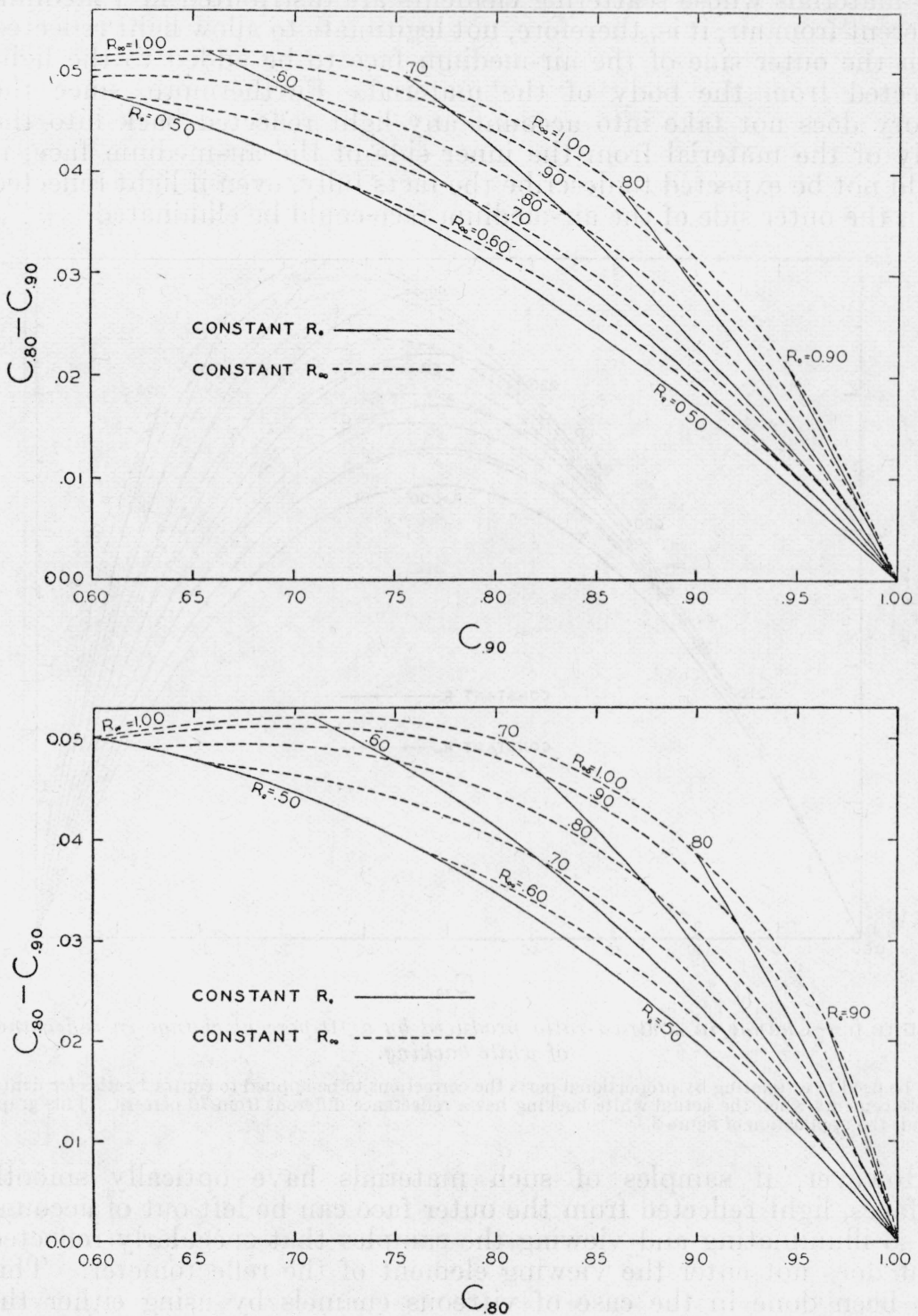

FIGURE 5.-Change in contrast-ratio produced by a 10-percent change in reflectance of white backing.

To be used (upper graph) in estimating by proportional parts the corrections to be applied to contrast ratios for paper when the actual white backing has a reflectance different from 89 percent, also (lower graph) for vitreous enamels and paints when the actual white backing has a reflectance different from 80 percent. This graph extends the application of figures 1 and 2 .

the medium (uncoated papers, cold-water-paint films), and (2) those in which the medium is not air (vitreous enamels, dental silicate cements). 
The pertinence of this classification lies in the assumption by Kubelka and Munk that the hypothetical material is homogeneous. For materials whose scattering elements are distributed in a medium different from air, it is, therefore, not legitimate to allow light reflected from the outer side of the air-medium face to be added to the light reflected from the body of the material. Furthermore, since the theory does not take into account any light reflected back into the body of the material from the inner side of the air-medium face, it could not be expected to describe the facts fully, even if light reflected from the outer side of the air-medium face could be eliminated.

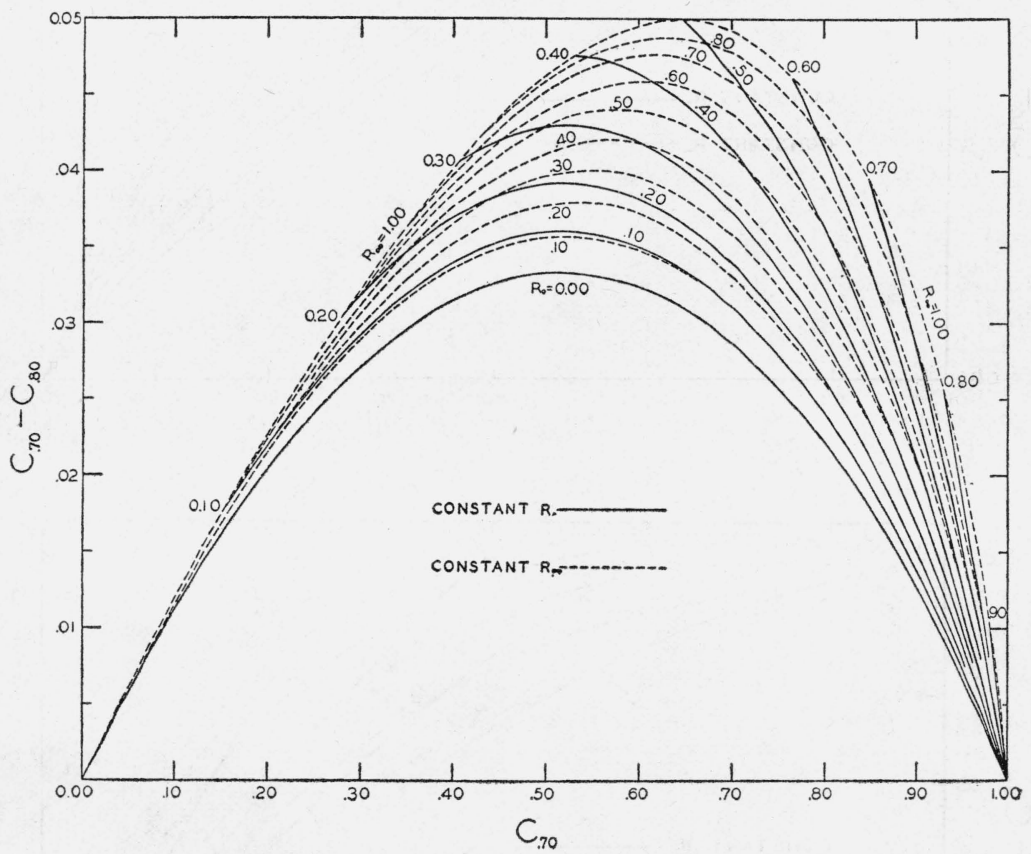

FIGURE 6.-Change in contrast-ratio produced by a 10-percent change in reflectance of white backing.

To be used in estimating by proportional parts the corrections to be applied to contrast ratios for dental silicate cements when the actual white backing has a reflectance different from 70 percent. This graph extends the application of figure 3.

However, if samples of such materials have optically smooth surfaces, light reflected from the outer face can be left out of account by so illuminating and viewing the samples that specularly reflected light does not enter the viewing element of the reflectometer. This has been done in the case of vitreous enamels by using either the Priest-Lange reflectometer ${ }^{8}$ or the Hunter reflectometer in either its visual ${ }^{9}$ or photoelectric ${ }^{10}$ form. The specimens of dental silicate cement do not have optically smooth surfaces, however, and in this case the effect of first-surface reflection was largely avoided by covering the sample with a film of water.

${ }^{8}$ I. G. Priest, The Priest-Lange reflectometer applied to nearly white porcelain enamels, J. Research NBS 15, 529 (1935) RP 847.

R. S. Hunter, $A$ reflectometer and color comparator, Sci. Sec. Cir. C461, National Paint, Varnish, and Lacquer Assn., Washington, D. C. (April 1934).

${ }_{10}$ R. S. Hunter, A null method photoelectric reflectometer, J. Opt. Soc. Am. 26, 225 (1936); Bul. Am. Ceramic Soc. 15, 79 (1936); Better Enameling 7, 12 (March 1936). 
Similar considerations govern determinations of the effective reflectance of the backing, although their neglect may be expected to introduce considerably smaller discrepancies except for specimens of very low opacity. If the sample be in optical contact with a backing which absorbs light sufficiently strongly, the effective reflectance of the backing may, without significant error, be set at zero, but if the optical contact be broken, the film of air so introduced raises the effective reflectance of the backing by as much as 0.12 . In the case of vitreous enamels and oil paint films, the ordinary method of preparing specimens insures this optical contact. In our measurement of dental silicate cements, a water film was introduced between sample and backing and produced the same effect. The water film which surrounded the sample served also to protect the cement from changes by contact with air.

For materials whose medium is air (papers, cold-water-paint films), reflection at the surface need not be excluded since this reflection is quite homogeneous with other reflections taking place within the body of the material and is accounted for by the Kubelka-Munk formula. Indeed, for highly calendered papers which exhibit considerable gloss, a better agreement might be expected if provision is made to include specularly reflected light in the measurements. This could be done either by adding a correction to the apparent reflectance measured by the Priest-Lange or the Hunter reflectometer, or by using the Davis photoelectric opacimeter ${ }^{11}$ which, in the manufactured form, includes specularly reflected light in the measurement.

None of these instruments either illuminates the sample by perfectly diffused light or measures the total amount reflected at all angles. The materials investigated, however, scatter light sufficiently completely that fair agreement may be hoped for with the KubelkaMunk formulation, which assumes perfect diffusion.

\section{PREPARATION OF SAMPLES: RESULTS AND DISCUSSION}

\section{VITREOUS ENAMELS}

By W. N. Harrison and B. J. Sweo

In a study of the reflectance characteristics of opaque white vitreous enamel, cognizance should be taken of the constitution of the material. It is a suspension of various solid and gaseous occlusions in a glassy matrix and exists at room temperature in a state of arrested reaction. The solid particles usually are composed partly of undissolved materials contained in the raw batch or added to the fritted batch before grinding, or both, and partly of matter which has been in solution in the molten material but which crystallized out within a limited temperature range below the solution temperature. The gaseous particles are probably partly occluded air and partly products of reaction between the materials used (including the metal base), and of volatilization.

At and near room temperature the progress toward equilibrium between the components is ordinarily imperceptible, but above 500 to $600^{\circ} \mathrm{C}$ the rates of reaction between the constituents probably increase rapidly with temperature, as does the fluidity of the suspending medium.

${ }^{11}$ M. N. Davis, A simple and reliable photoelectric opacity tester, Tech. Assn. Pap. [16], 277 (1933). 
These facts are important, especially because in applying enamel to metal the powdered-enamel coating is fired at temperatures varying approximately from 700 to $950^{\circ} \mathrm{C}$, depending on the composition, and at such temperatures these reactions and consequent modification of characteristics proceed, though naturally at slower rates than those which prevail when the raw batch is originally "smelted" to form the frit at temperatures several hundred degrees higher. While this comparative slowness of reaction at firing temperatures, and the brevity of exposure (only a few minutes are required for small pieces), combine to repress changes in characteristics during firing, the fact cannot

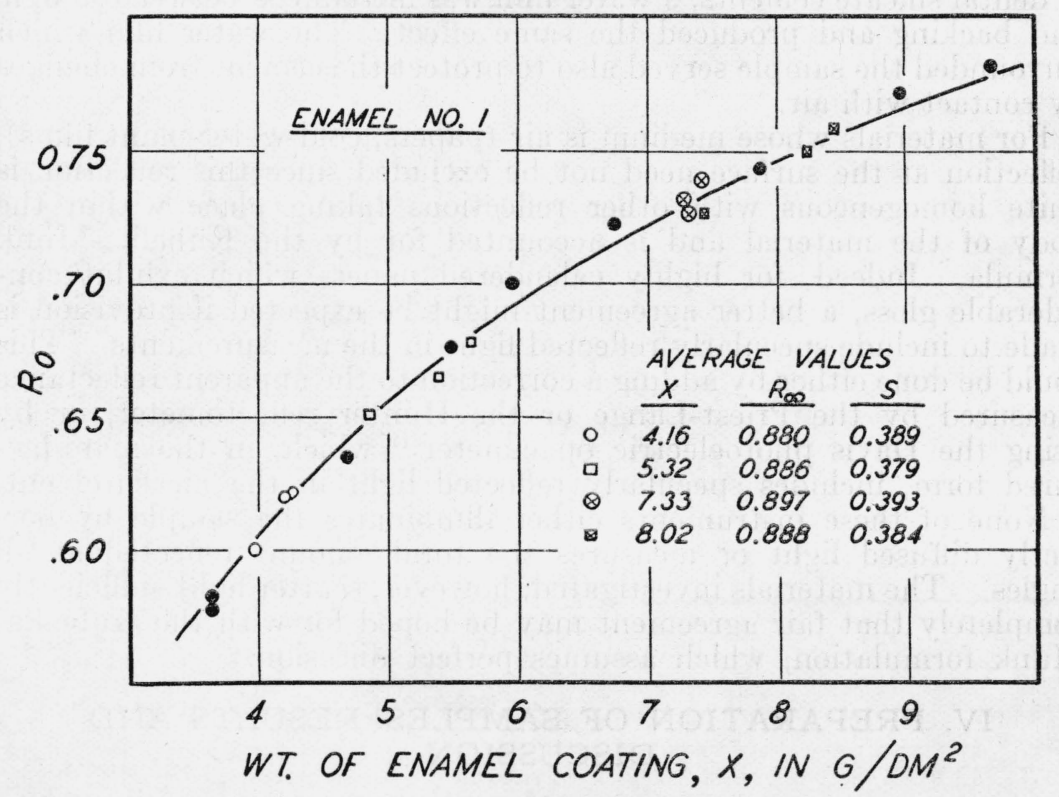

Figure 7.-Constants determined by contrast-ratio method.

Four determinations were made from the respective averages of four sets of three specimens each. The values of $R_{0}$ for these specimens are shown as circles, squares, crossed circles, and crossed squares, respectively, and the constants for each determination are shown. The solid circles represent determinations of weight of coating versus reflectance which were independent of the contrast-ratio specimens. The curve was plotted from the average values of the respective constants.

be overlooked that changes of this type, and also some degree of interpenetration between a white cover coat and a black undercoat, do occur.

The purpose of the work on enamels was to determine whether, in spite of their heterogeneity and comparative instability at firing temperatures, the relations between apparent reflectance and thickness within practical limits could be satisfactorily expressed in terms of the Kubelka-Munk constants on the assumption that apparent reflectance, $A$, gives an adequate evaluation of reflectance, $R$. In accord with the assumption, the determined values of $A$ are hereinafter referred to as $R$.

It soon became evident that the inspection areas covered by most reflectometers (usually $6 \mathrm{~cm}^{2}$ or less) are not large enough to be representative of specimens $1 \mathrm{dm}$ square having thin coatings of low opacity because such coatings are generally not sufficiently uniform. Since 
for practical reasons it is not feasible to reduce the size of enameled specimens drastically below $1 \mathrm{dm}^{2}$, a reflectometer covering a large fraction of this area was desired, and the Hunter Photox photo-electric reflectometer was selected. The instrument used covers an inspection area which is nearly circular and about $7 \mathrm{~cm}$ in diameter.

\section{(a) CONTRAST-RATIO METHOD}

The first method of study was to determine the contrast ratio $\left(C_{0.80}\right)$ and from this value, together with the reflectance $\left(R_{0}\right)$ of coatings of known weight per unit area $(X)$ over black backing, to estimate the constants, reflectivity $\left(R_{\infty}\right)$ and coefficient of scatter $(S)$, by means of the chart shown in figure 2. This method involved the preparation of test blanks with a black enamel on one-half and a white enamel of reflectance 0.80 on the other half. ${ }^{12}$

Figure 7 is representative of the more favorable results obtained by this method. The data corresponding to this figure, which were obtained from highly opaque enamel frit with no opacifier added at the mill, are given in table 1.

TABLE 1.-Reflectance data for enamel 1, contrast-ratio method

\begin{tabular}{|c|c|c|c|c|c|c|c|c|}
\hline \multirow{2}{*}{$\begin{array}{l}\text { Reflectance of } \\
\text { backing, } R^{\prime}\end{array}$} & \multirow{2}{*}{$\begin{array}{l}\text { Weight } \\
\text { of enamel, } \\
\frac{X}{}\end{array}$} & \multicolumn{2}{|c|}{$\begin{array}{c}\text { Reflectance of coating } \\
\text { over- }\end{array}$} & \multirow{2}{*}{$\begin{array}{l}R_{0} / R_{R^{\prime}} \\
\equiv C_{R}^{\prime}\end{array}$} & \multirow{2}{*}{$\begin{array}{l}\text { Opacity, } \\
C_{0.80}\end{array}$} & \multirow{2}{*}{$\begin{array}{c}\text { Scatter- } \\
\text { ing } \\
\text { power, } \\
S X\end{array}$} & \multirow{2}{*}{$\begin{array}{l}\text { Coeffi- } \\
\text { cient of } \\
\text { seatter, } \\
S\end{array}$} & \multirow{2}{*}{$\begin{array}{c}\text { Reflec- } \\
\text { tivity, } \\
R_{\infty}\end{array}$} \\
\hline & & $\begin{array}{c}\text { Black } \\
\text { backing, } \\
R_{0}\end{array}$ & $\begin{array}{c}\text { White } \\
\text { baoking, } \\
R_{R^{\prime}}\end{array}$ & & & & & \\
\hline $\begin{array}{r}0.814 \\
.825 \\
.812 \\
\end{array}$ & $\begin{array}{r}\mathrm{g} / \mathrm{dm} \mathrm{m}^{2} \\
3.99 \\
4.22 \\
4.27\end{array}$ & $\begin{array}{r}0.599 \\
.616 \\
.618 \\
\end{array}$ & $\begin{array}{r}0.840 \\
.846 \\
.840\end{array}$ & & & & & \\
\hline Average_..... 817 & 4.16 & .612 & .842 & 0.727 & 0.735 & 1.62 & 0.389 & 0.880 \\
\hline $\begin{array}{r}.810 \\
.813 \\
.815 \\
\end{array}$ & $\begin{array}{l}4.88 \\
5.41 \\
5.66 \\
\end{array}$ & $\begin{array}{l}.650 \\
.664 \\
.678 \\
\end{array}$ & $\begin{array}{l}.842 \\
.849 \\
.850 \\
\end{array}$ & & & & & - \\
\hline Average...... 813 & 5.32 & .664 & .847 & .784 & .790 & 2.04 & .379 & .886 \\
\hline $\begin{array}{r}.816 \\
.816 \\
.807 \\
\end{array}$ & $\begin{array}{l}\text { 7. } 31 \\
\text { 7. } 27 \\
\text { 7. } 41 \\
\end{array}$ & $\begin{array}{l}.726 \\
.732 \\
.739\end{array}$ & $\begin{array}{l}.858 \\
.859 \\
.859 \\
\end{array}$ & & & & - & - \\
\hline Average & 7. 33 & .732 & .859 & .852 & .857 & 2.88 & .393 & .897 \\
\hline $\begin{array}{l}.812 \\
.809 \\
.815\end{array}$ & $\begin{array}{l}7.43 \\
8.22 \\
8.41\end{array}$ & $\begin{array}{l}.726 \\
.749 \\
.758 \\
\end{array}$ & $\begin{array}{l}.856 \\
.859 \\
.860 \\
\end{array}$ & 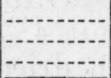 & 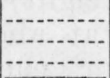 & - & 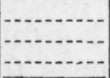 & - \\
\hline Average_.... 812 & 8. 02 & .744 & .858 & .867 & .872 & 3. 09 & .384 & .888 \\
\hline
\end{tabular}

The constants $R_{\infty}$ and $S$ were computed four times, from four groups of three specimens each, at different average thicknesses of the test coating. The $R_{0}$ values of these contrast-ratio specimens are shown in figure 7 as circles, squares, crossed circles, and crossed squares, respectively. The solid circles represent independently determined points, obtained from coatings over ordinary black-coated blanks, rather than contrast-ratio blanks.

It is seen that the four pairs of independently determined constants agree reasonably well with each other, and that all the experi-

\footnotetext{
12 The white and black backings could be used on separate specimens, but this procedure would involve the comparison of pairs of specimens with equal coatings of test enamel.
} 
mental points fall close to the theoretical line corresponding to the average value of the two constants.

Such fairly consistent results were not, however, obtained without close attention to numerous details, and even then not in all cases. This fact is probably due in part to sources of error peculiar to this method of test. Known deviations from 0.80 in the reflectance of the white backing were corrected for by means of figure 5, but any change in reflectance of the backing which might occur during the firing of the test coating could not be similarly corrected for, since both its direction and extent were unknown. Also, errors in reflectance measurements may be accentuated in the ratio of two reflectance measurements, from which the contrast ratio was determined. Further, the assumption that the enamel is applied in equal thicknesses to both ends of the specimen, although this condition was sought, is subject to more or less error, depending on the skill of the operator. Less opaque enamels appeared to be more affected by the sources of error, since in general results for them were less satisfactory.

No data in addition to table 1 and figure 7 are given for the contrast-ratio method, since the data obtained were largely of a preliminary nature and not suitable for drawing definite conclusions. Rather than make a more exhaustive study of this method, and the perfection of a dependable technique applicable to all classes of white enamel, the following method was investigated, which it was hoped would be less dependent upon carefully controlled technique and specialized skill for satisfactory reproducibility.

\section{(b) REFLECTIVITY METHOD}

(1) Technique.- In this method the reflectivity was determined by direct measurement of the reflectance of a thick coating. The thickness required may be seen from figure 2 to correspond to scattering powers $(S X)$ of 16 . for reflectivities up to 0.85 ; and even for reflectivity 0.90 , the reflectance $R_{0}$ for this scattering power differs from the reflectivity by only 0.005 . Preliminary data indicated that suitable scattering powers could be obtained by coatings of $75 \mathrm{~g} / \mathrm{dm}^{2}$.

Although reflectances of these heavy coatings cannot be used alone to obtain coefficients of scatter, they may be used for this purpose when combined with reflectance data for the thinner coatings encountered in commercial practice for wet-process enamels (4 to $9 \mathrm{~g} / \mathrm{dm}^{2}$, dry weight). Ordinarily one specimen was coated at about $4 \mathrm{~g} / \mathrm{dm}^{2}$, one at about $4 \frac{1 / 2}{2}$, and so on by approximately $1 / 2-\mathrm{g}$ increments to $9 \mathrm{~g} / \mathrm{dm}^{2}$, each dried coating being weighed by difference to the nearest $0.01 \mathrm{~g}$. However, for enamels having very low covering power, $P$, it was found advisable to use somewhat greater thicknesses.

To keep the firing practice as uniform as possible, the specimens in this range of thickness were fired in a single firing period (for the cover coat). The heavier coats were applied in two (or if necessary three) sprayings, any spray coat subsequent to the first being kept dry enough by adjustment of the spray gun to prevent its glossing over during spraying. (Without this precaution the application of two or more spray coats before firing was not uniformly successful.) The specimens coated with $75 \mathrm{~g} / \mathrm{dm}^{2}$ of enamel could be prepared in the same fashion, by spraying on numerous coats to be fired at once, but although this process was tried successfully, it was considered 
more practicable to dry out the enamel suspension known as "slip" and apply the powder by the dry process.

(2) Results.-Three enamels were tested by the reflectivity method; one enamel of high covering power, $P$, one low and one interme-

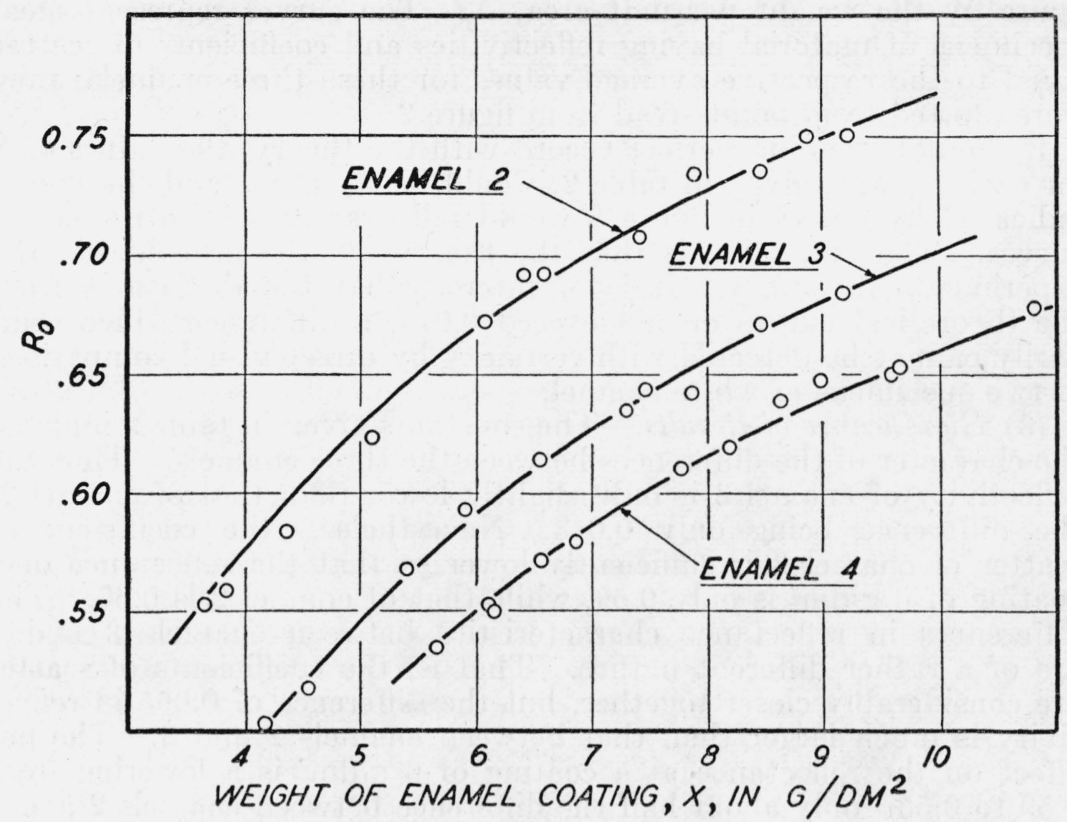

Figure 8.-Constants determined by direct observation of reflectivity and use of the observed value $R_{\infty}$, with plotted values of $R_{0}$ to read coefficient of scatter from figure 2.

diate. All were given equal grinding treatment with 7 parts by weight of clay for each 100 parts of frit, and no opacifier was added at the mill.

The results are shown in table 2 and figure 8.

TABLE 2.-Reflectance data for enamels 2, 3, and 4, reflectivity method

\begin{tabular}{|c|c|c|c|c|c|c|c|c|c|c|c|}
\hline \multicolumn{4}{|c|}{ Enamel 2 a } & \multicolumn{4}{|c|}{ Enamel 3 b } & \multicolumn{4}{|c|}{ Enamel $4^{\circ}$} \\
\hline$X$ & $R_{0}$ & $S X$ & $S$ & $X$ & $R_{0}$ & $S X$ & $S$ & $X$ & $R_{o}$ & $S X$ & $S$ \\
\hline $\begin{array}{l}\mathrm{g} / \mathrm{dm}^{2} \\
3.65 \\
3.83 \\
4.35 \\
5.08\end{array}$ & $\begin{array}{r}0.553 \\
.559 \\
.584 \\
.624\end{array}$ & $\begin{array}{l}1.25 \\
1.28 \\
1.43 \\
1.69\end{array}$ & $\begin{array}{r}0.342 \\
.334 \\
.329 \\
.333\end{array}$ & $\begin{array}{r}\mathrm{g} / \mathrm{dm}^{2} \\
4.16 \\
4.53 \\
5.40 \\
5.87\end{array}$ & $\begin{array}{r}0.501 \\
.518 \\
.567 \\
.594\end{array}$ & $\begin{array}{l}1.02 \\
1.09 \\
1.33 \\
1.50\end{array}$ & $\begin{array}{r}0.245 \\
.241 \\
.246 \\
.255\end{array}$ & $\begin{array}{r}\mathrm{g} / \mathrm{dm}^{2} \\
5.65 \\
6.10 \\
6.12 \\
6.55\end{array}$ & $\begin{array}{r}0.536 \\
.552 \\
.551 \\
.572\end{array}$ & $\begin{array}{l}1.21 \\
1.29 \\
\text { 1. } 29 \\
1.41\end{array}$ & $\begin{array}{l}0.214 \\
.212 \\
.211 \\
.215\end{array}$ \\
\hline $\begin{array}{l}6.06 \\
6.40 \\
6.58 \\
7.42\end{array}$ & $\begin{array}{l}.673 \\
.692 \\
.693 \\
.708\end{array}$ & \begin{tabular}{l|}
2.12 \\
2.32 \\
2.34 \\
2.52
\end{tabular} & $\begin{array}{l}.350 \\
.362 \\
.356 \\
.340\end{array}$ & $\begin{array}{l}6.55 \\
7.30 \\
7.49 \\
7.88\end{array}$ & $\begin{array}{l}.616 \\
.635 \\
.644 \\
.643\end{array}$ & $\begin{array}{l}1.64 \\
1.79 \\
1.87 \\
1.86\end{array}$ & $\begin{array}{l}.250 \\
.245 \\
.250 \\
.236\end{array}$ & $\begin{array}{l}6.85 \\
7.78 \\
8.21 \\
8.65\end{array}$ & $\begin{array}{l}.580 \\
.611 \\
.619 \\
.639\end{array}$ & $\begin{array}{l}1.46 \\
1.68 \\
1.74 \\
1.92\end{array}$ & $\begin{array}{l}.213 \\
.216 \\
.212 \\
.223\end{array}$ \\
\hline $\begin{array}{l}7.88 \\
8.46 \\
8.87 \\
9.22\end{array}$ & $\begin{array}{l}.734 \\
.736 \\
.750 \\
.751\end{array}$ & \begin{tabular}{l|}
2.89 \\
2.92 \\
3.16 \\
3.18
\end{tabular} & $\begin{array}{l}.367 \\
.345 \\
.356 \\
.345\end{array}$ & \begin{tabular}{r}
8.47 \\
9.18 \\
\hdashline-2 \\
\end{tabular} & \begin{tabular}{c}
.672 \\
.686 \\
\hdashline.--- \\
\end{tabular} & $\begin{array}{c}2.12 \\
2.28 \\
\end{array}$ & $\begin{array}{r}.250 \\
.249 \\
\end{array}$ & $\begin{array}{r}8.99 \\
9.60 \\
9.64 \\
10.81\end{array}$ & $\begin{array}{l}.648 \\
.650 \\
.653 \\
.678\end{array}$ & $\begin{array}{l}2.01 \\
2.02 \\
2.07 \\
2.35\end{array}$ & $\begin{array}{l}.224 \\
.210 \\
.215 \\
.217\end{array}$ \\
\hline A verage. ..... & & & 0.348 & & & & 0.247 & & & & 0.215 \\
\hline
\end{tabular}

a $R_{\infty}=0.901,0.897$; average 0.899 .

- $R_{\infty}=0.884,0.887$; average 0.886 .

- $R_{\infty}=0.824,0.818$; a verage 0.821 .

$7187-37-5$ 
From the average values of $R_{\infty}$, and the observed values of $R_{0}$ for the respective specimens in the weight-reflectance series, the scattering power, $S X$, for each such specimen was read from figure 2 , and the coefficient of scatter, $S$, was computed in each case by dividing this figure by the weight per unit area, $X$. The curves represent ideal specimens of material having reflectivities and coefficients of scatter equal to the respective average values for these three enamels; they were plotted from points read from figure 2 .

If the data were in perfect accord with the theory, the values of $S$ for each enamel, given in table 2 , would be constant, and the points indicated by circles in figure 8 would fall exactly on the respective curves. The indication is that the theory fits the data within the experimental accuracy. It is of interest that the deviations from the theoretical curves do not exceed 0.013 , a difference which ordinarily cannot be detected with certainty by direct visual comparison of two specimens of white enamel.

(3) Significance of Results.-The constants given in table 2 indicate the character of the differences between the three enamels. Thus the reflectivity of enamel 3 is only slightly lower than that of enamel 2, the difference being only 0.013. Nevertheless, the coefficient of scatter of enamel 3 is sufficiently lower so that the reflectance of a coating of $6 \mathrm{~g} / \mathrm{dm}^{2}$ is only 0.59 , while that of enamel 2 is 0.67 . The differences in reflectance characteristics between enamels 3 and 4 are of a rather different nature. That is, the coefficients of scatter are considerably closer together, but the difference of 0.065 in reflectivity is much larger than that between enamels 2 and 3 . The net effect on the reflectance at a coating of $6 \mathrm{~g} / \mathrm{dm}^{2}$ is a lowering from 0.59 to 0.55 - only about half the difference between enamels 2 and 3 at this weight of coating.

The constants may also be used in connection with figure 2 to determine the covering power, $P$, of each enamel. These values are nearly $0.79,0.71$, and 0.68 for enamels 2,3 , and 4 , respectively. By comparing these values with the average constants in table 2 , it is seen that the changes in covering power, $P$, follow the changes in coefficient of scatter, $S$, much more closely than they do the changes in reflectivity, $R_{\infty}$, of these three typical "white" enamels.

\section{(c) DUAL-THICKNESS METHOD}

The procedure used in these tests was (a) to obtain a reflectance, $R_{0}$, for a wet-process coating of about $18 \mathrm{~g} / \mathrm{dm}^{2}$ from the average observed reflectance of two specimens having that weight of coating, and (b) in the lower-weight range, to determine the reflectance for a coating of one-third the above-stated thickness by interpolation from a set of specimens prepared as previously described. The constants were determined from figure 2 , as illustrated by the following case, the data for which are shown in figure 9. The average coating of the two most heavily coated specimens was $17.85 \mathrm{~g} / \mathrm{dm}^{2}$ and the average reflectance was 0.833 . The reflectance corresponding to $5.95 \mathrm{~g} / \mathrm{dm}^{2}$ (one-third of $17.85 \mathrm{~g} / \mathrm{dm}^{2}$ ) was read by interpolation on a smooth curve closely representing the data between 4 and $9 \mathrm{~g} / \mathrm{dm}^{2}$ and found to be 0.687 . The problem was, then, to find a constant-reflectivity line on figure 2 such that the scattering power, $S X$, at a reflectance of 0.833 is three times the scattering power at a reflectance of 0.687 . 
It was found by inspection that the line for $R_{\infty}=0.87$ approximately meets this condition. The ratio of the scattering powers is 2.94 for $R_{\infty}=0.87$ and 3.15 for $R_{\infty}=0.86$, and by interpolation the ratio is equal to 3.0 when $R_{\infty}=0.867$, which is, therefore, the reflectivity sought. ${ }^{13}$ The coefficient of scatter, $S$, was found by dividing out $X$ from either of the two scattering powers $S X$ which served to identify the reflectivity. The solid line in figure 9 was located from constants

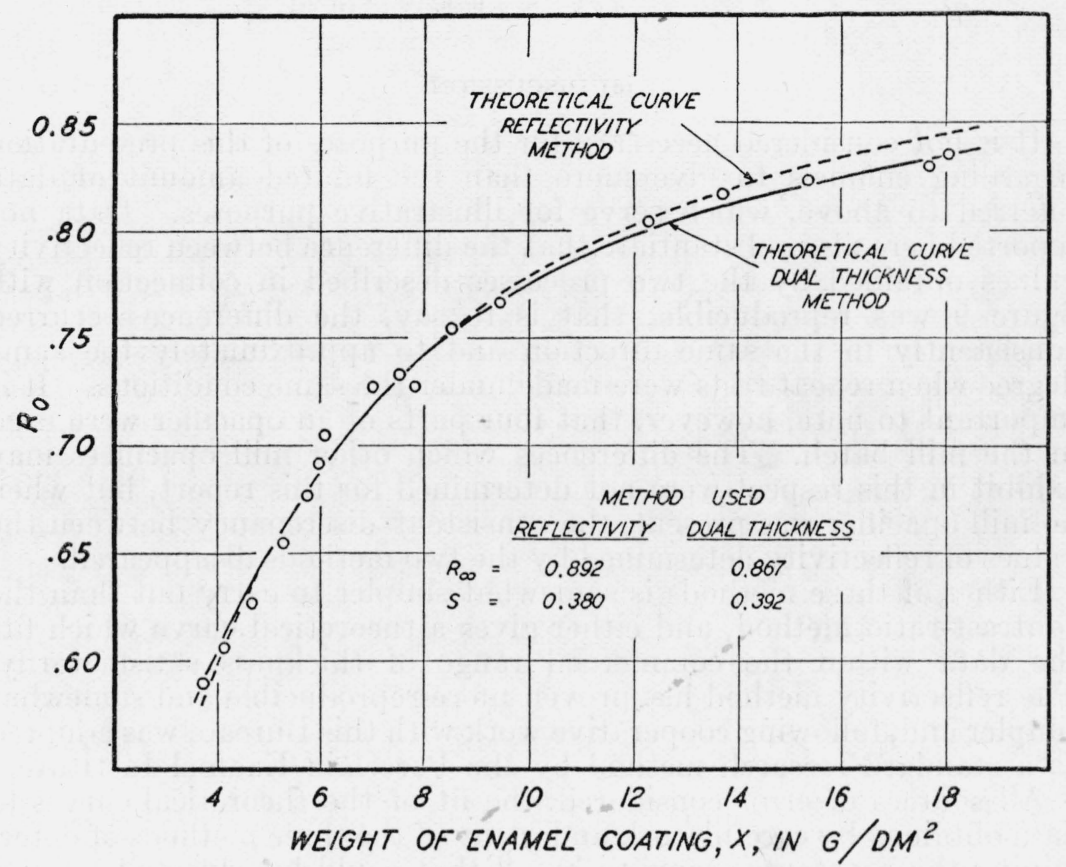

FIGURE 9.-Continuous line corresponds to constants determined by the dual-thickness method, dotted line to constants determined by reflectivity method.

determined in this fashion. The points between 12 and $16 \mathrm{~g} / \mathrm{dm}^{2}$ represent supplementary check values, and were not used in determining the constants.

For comparison the reflectivity was also observed directly, as previously described, from specimens coated by dry process with 75 $\mathrm{g} / \mathrm{dm}^{2}$ of this enamel. The observed value was 0.892 , which is 0.025 greater than that computed from the wet-process data. The dotted line in figure 9 was drawn from this value of $R_{\infty}$ and the value of $S$ computed by figure 2 from it and from the same point on the weightreflectance curve used before, namely, $X=5.93$ and $R_{0}=0.687$. The constants obtained by the two methods are given in table 3 .

It is seen from figure 9 that the curve obtained by either method fits the observed points in the commercial range 4 to $9 \mathrm{~g} / \mathrm{dm}^{2}$ within experimental accuracy, and that above this range some points are closer to one curve and some to the other.

\footnotetext{
${ }^{13}$ A set of curves giving a rapid explicit solution for reflectivity, to replace the trial and error solution by means of figure 2 , could be prepared and should be available if this method were to be used regularly.
} 
TABLE 3.-Medium-opacity enamel

[Four parts opacifier $A$ added at the mill]

\begin{tabular}{|c|c|c|c|}
\hline \multicolumn{2}{|c|}{ Reflectivity method } & \multicolumn{2}{|c|}{ Dual-thickness method } \\
\hline$R_{\infty}$ & $S$ & $R_{\infty}$ & $S$ \\
\hline 0.892 & 0.380 & 0.867 & 0.392 \\
\hline
\end{tabular}

(d) DISCUSSION

It is not considered necessary for the purposes of this presentation regarding enamels to give more than the limited amount of data referred to above, which serve for illustrative purposes. Data not reported here also substantiate that the difference between reflectivity values obtained by the two processes described in connection with figure 9 was reproducible; that is to say, the difference occurred consistently in the same direction and to approximately the same degree when repeat tests were made under the same conditions. It is important to note, however, that four parts of an opacifier were used in the mill batch. The differences which other mill opacifiers may exhibit in this respect were not determined for this report, but when no mill opacifier was present, the consistent discrepancy between the values of reflectivity determined by the two methods disappeared.

Either of these methods is somewhat simpler to carry out than the contrast-ratio method, and either gives a theoretical curve which fits the data within the commercial range of thickness satisfactorily. The reflectivity method has proven more reproducible and somewhat simpler and, following cooperative work with this Bureau, was adopted as a standard research method by the Porcelain Enamel Institute. ${ }^{14}$

All sources of error considered, the fit of the theoretical curves to data obtained by careful work under any of the three methods of determining the constants seems to be all that could be expected. Since each of the two Kubelka-Munk constants has a physical significance, as revealed in the respective definitions, the results give a basis of comparing different enamels and mill batches, and determining the character of effects produced by given changes in enamels or mill batches, which offers much promise of usefulness in the field of vitreous enamels.

\section{COLD-WATER PAINTS}

\section{By E. F. Hickson and A. J. Eickhoff}

Cold-water paints may be described as a mixture of materials with some water-soluble vehicle (casein, glue, etc.). Water acts merely as a thinner or solvent necessary for purposes of application. Thus, after drying, the film is essentially a pigment with air as the medium.

This work was undertaken to determine whether or not the fundamental optical properties of a dry cold-water paint film followed the equations of Kubelka and Munk.

14 Reflectance Test for Opaque White Porcelain Enamels, obtainable from the Porcelain Enamel Institute, 612 N. Michigan A ve., Chicago, Ill. 


\section{(a) PREPARATYON OF SAMPLES}

The cold-water paints studied are supplied in the form of a paste. The fraction, $K$, by weight of dry solids in each paste was first determined; then a paint was made from each paste by adding water until the weight of dry solids was equal to that of the water in the paint $(K=0.5)$. The density, $D$, of this paint was then determined by weighing a known volume of it.

A number of single coats of each paint were prepared, the coats ranging from light to heavy. It was found that small quantities and excessively large quantities of paint are somewhat difficult to spread evenly. A coat of about 6 to $7 \mathrm{ml}$ of paint $(K=0.5)$ per square foot seems to give the most desirable working properties. These coats were spread on lacquer-sized sheets of heavy paper marked with alternate $1 / 2$ in. black and white bands in a diamond-shaped design with a black and a white square in the center. The apparent reflectance of the black portions of the sheet is nearly zero on the Hunter reflectometer, that of the white portions about 0.80 . The paint was spread as evenly as possible by means of a badger-hair brush, and the weight of paint applied to a sheet was determined by weighing container and brush before and after spreading. The weight of dry solids was, of course, one-half the weight of the paint ( $K=0.5$ ).

\section{(b) MEASUREMENTS OF APPARENT REFLECTANCE}

For purposes of examination, the area averaged by the reflectometer should be relatively large. The Hunter Photox photoelectric reflectometer answered this requirement. The instrument used measures the apparent reflectance of an elliptical area of about $40 \mathrm{~cm}^{2}$. The apparent reflectance of each sample of each paint was measured both from the white central square of the sheet and from the black central square, the squares having been included on the lacquered sheet for this purpose. These values of apparent reflectance were taken as $R_{0}$ and $R_{0.80}$, respectively.

\section{(c) REDUCTION OF DATA}

Tables 4, 5, and 6 give detailed data for two paints, $a$ and $c$; and table 7 gives a summary for the nine paints studied. Table 5 gives results of repeat measurements on the same paint $(a)$ dealt with in table 4 ; it indicates the experimental uncertainty of the reflectance measurements, most of which is ascribable to difficulty of applying the paint evenly. Contrast ratio, $C_{0.80}$, was computed as $R_{0} / R_{0.80}$. The reflectivity, $R_{\infty}$, and scattering power, $S X$, were read from the reflectance-opacity chart (fig. 2). It is not possible to obtain a reliable measurement of the thickness, $X$, of the dry paint films, nor is such a measurement of very great interest. The thickness, $X$, has been expressed in three ways: first, as the thickness of the wet coat, in microns; second, as the weight per unit area of dry solids, $\mathrm{g} / \mathrm{ft}^{2}$; and third, as the volume of original paste per unit area, $\mathrm{ml} / \mathrm{ft}^{2}$. The thickness of the wet film in microns has been used as an approximation to the thickness of the dry paint films for the purpose of comparing the properties of cold-water-paint films with other scattering materials, see section V. If the paint were supplied, as many cold-water paints are, in the form of a dry powder sold by weight, the most useful measure of thickness of the coat would be weight, $M$, of dry solids per unit area; but since these paints were supplied in the form of paste 
sold by volume, the measure of thickness, $X$, used is volume, $V$, of original paste per unit area. This volume, $V$, is computed from the fraction, $K$, by weight of dry solids in the original paste, and the density, $D$, of the paint made up so that $K=0.5$ according to the readily derived relation:

$$
V=M[(1-K) / K+2 / D-1]
$$

TABLE 4.-Detailed data for paint a2

\begin{tabular}{|c|c|c|c|c|c|c|c|}
\hline $\begin{array}{l}\text { Weight, } M \text {, of } \\
\text { dry solids }\end{array}$ & $\begin{array}{l}\text { Reflectance } \\
\text { on black } R_{0}\end{array}$ & $\begin{array}{l}\text { Reflectance } \\
\text { on white } R_{0.80}\end{array}$ & $\begin{array}{c}\text { Contrast ratio } \\
\text { black/white } \\
C_{0.80}\end{array}$ & $\begin{array}{c}\text { Volume, } V \text {, } \\
\text { of paste }\end{array}$ & $R_{\infty}$ & $S X$ & $\begin{array}{l}S(X \text { in } \\
\left.\mathrm{ml} / \mathrm{ft} .{ }^{2}\right)\end{array}$ \\
\hline $\begin{array}{l}\text { a g/ft } 2 \\
2.52 \\
2.77 \\
2.97 \\
3.92 \\
3.94\end{array}$ & $\begin{array}{r}0.785 \\
.765 \\
.760 \\
.770 \\
.830\end{array}$ & $\begin{array}{r}0.870 \\
.870 \\
.870 \\
.865 \\
.880\end{array}$ & $\begin{array}{r}0.902 \\
.880 \\
.874 \\
.890 \\
.944\end{array}$ & $\begin{array}{r}m l / f t{ }^{2} \\
2.04 \\
2.25 \\
2.41 \\
3.18 \\
3.19\end{array}$ & $\begin{array}{r}0.912 \\
.923 \\
.930 \\
.907 \\
.906\end{array}$ & $\begin{array}{l}3.85 \\
3.35 \\
3.24 \\
3.52 \\
5.50\end{array}$ & $\begin{array}{l}1.9 \\
1.5 \\
1.3 \\
1.1 \\
1.7\end{array}$ \\
\hline $\begin{array}{l}4.28 \\
5.08 \\
5.49 \\
5.79 \\
6.02\end{array}$ & $\begin{array}{l}.840 \\
.850 \\
.845 \\
.855 \\
.865\end{array}$ & $\begin{array}{l}.880 \\
.890 \\
.885 \\
.895 \\
.900\end{array}$ & $\begin{array}{l}.955 \\
.955 \\
.955 \\
.955 \\
.961\end{array}$ & $\begin{array}{l}3.47 \\
4.12 \\
4.45 \\
4.69 \\
4.88\end{array}$ & $\begin{array}{l}.900 \\
.916 \\
.908 \\
.925 \\
.930\end{array}$ & $\begin{array}{l}6.2 \\
6.3 \\
6.3 \\
6.5 \\
7.0\end{array}$ & $\begin{array}{l}1.8 \\
1.5 \\
1.4 \\
1.4 \\
1.4\end{array}$ \\
\hline Average....... & & & . & ......... & 0.916 & 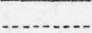 & 1.50 \\
\hline
\end{tabular}

a These hybrid units are widely used by paint technologists. The more rational units, grams per square decimeter and mililiters per square decimeter, have on this account not been used here.

TABLE 5.-Detailed data for paint a1

\begin{tabular}{|c|c|c|c|c|c|c|c|}
\hline $\begin{array}{l}\text { Weight, } M \text {, of } \\
\text { dry solids }\end{array}$ & $\begin{array}{l}\text { Reflectance } \\
\text { on black } R_{0}\end{array}$ & $\begin{array}{l}\text { Reflectance } \\
\text { on white } R_{0.80}\end{array}$ & $\begin{array}{c}\text { Contrast ratio } \\
\text { black/white } \\
C_{0.80}\end{array}$ & $\begin{array}{c}\text { Volume, } V \text {, } \\
\text { of paste }\end{array}$ & $R_{\infty}$ & $S X$ & $\begin{array}{l}S(X \text { in } \\
\left.\mathrm{ml} / \mathrm{it} .{ }^{2}\right)\end{array}$ \\
\hline $\begin{array}{r}g / f t \text { ' } \\
2.86 \\
3.26 \\
3.39 \\
3.92 \\
4.29\end{array}$ & $\begin{array}{r}0.770 \\
.790 \\
.790 \\
.820 \\
.810\end{array}$ & $\begin{array}{r}0.875 \\
.880 \\
.870 \\
.880 \\
.880\end{array}$ & $\begin{array}{r}0.880 \\
.898 \\
.908 \\
.932 \\
.920\end{array}$ & $\begin{array}{r}m l / f t{ }^{2} \\
2.32 \\
2.64 \\
2.75 \\
3.18 \\
3.48\end{array}$ & $\begin{array}{r}0.940 \\
.940 \\
.908 \\
.912 \\
.923\end{array}$ & $\begin{array}{l}3.40 \\
3.85 \\
4.07 \\
4.97 \\
4.48\end{array}$ & $\begin{array}{l}1.5 \\
1.5 \\
1.5 \\
1.6 \\
1.3\end{array}$ \\
\hline $\begin{array}{l}4.34 \\
4.92 \\
5.17 \\
5.74 \\
5.93\end{array}$ & $\begin{array}{l}.830 \\
.845 \\
.845 \\
.855 \\
.860\end{array}$ & $\begin{array}{l}.885 \\
.890 \\
.890 \\
.895 \\
.890\end{array}$ & $\begin{array}{l}.938 \\
.950 \\
.950 \\
.955 \\
.966\end{array}$ & $\begin{array}{l}3.52 \\
3.99 \\
4.19 \\
4.65 \\
4.81\end{array}$ & $\begin{array}{l}.920 \\
.920 \\
.920 \\
.926 \\
.910\end{array}$ & $\begin{array}{l}5.30 \\
6.00 \\
6.00 \\
6.50 \\
7.30\end{array}$ & $\begin{array}{l}1.5 \\
1.5 \\
1.4 \\
1.4 \\
1.5\end{array}$ \\
\hline A verage....... & -..... & 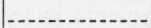 & ....... & -....... & 0.922 & & 1.47 \\
\hline
\end{tabular}

TABLe 6.-Detailed data for paint $c$

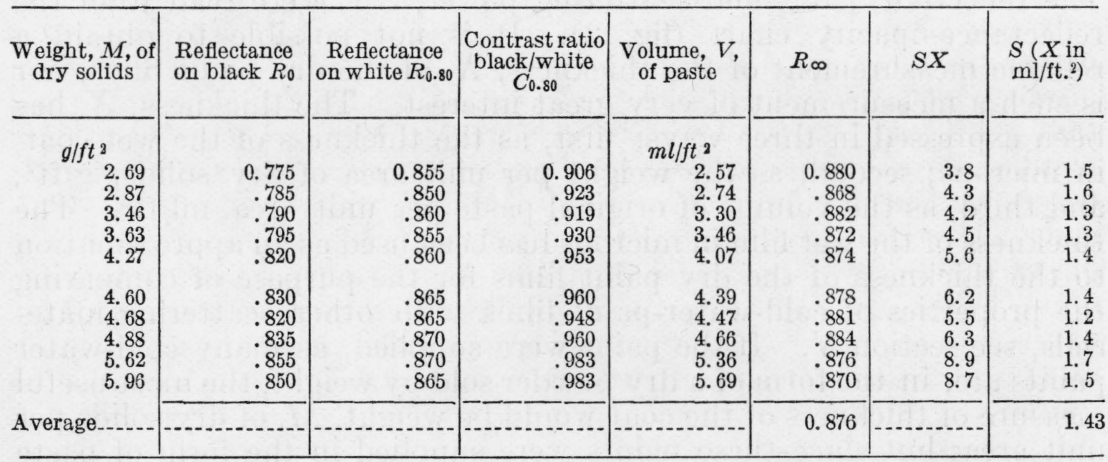


TABLE 7.-Summary for cold-water paints

\begin{tabular}{|c|c|c|c|c|c|c|c|c|c|}
\hline Paint & $\begin{array}{c}\text { Weight, } \\
M \text {, of } \\
\text { dry sol- } \\
\text { ids for } \\
C_{0.80}= \\
0.93\end{array}$ & $\begin{array}{l}\text { Fraction, } \\
K \text { by } \\
\text { weight } \\
\text { of dry } \\
\text { solids } \\
\text { in paste }\end{array}$ & \begin{tabular}{|l} 
Density, \\
$D$ of \\
paint \\
having \\
$K$ ad- \\
justed \\
to 0.5
\end{tabular} & $\begin{array}{c}\text { Volume, } \\
V \text { of } \\
\text { paste for } \\
C_{0.80}= \\
0.93\end{array}$ & $R_{\infty}$ & $\begin{array}{l}S(X \text { in } \\
\left.\mathrm{ml} / / \mathrm{ft}{ }^{2}\right)\end{array}$ & $\begin{array}{c}S X \text { for } \\
C_{0.80}=0.93\end{array}$ & $\begin{array}{c}\text { Thickness, } \\
X \text { for } \\
C_{0.80}=0.93 \\
\text { found from } \\
\text { theory, } \\
\text { ml/sq ft } \\
\text { (compare } \\
\text { with } V \text { ) }\end{array}$ & $\begin{array}{l}\text { Thickness, } X \\
\text { for } C_{0.80}=0.93 \\
\text { for } R \infty \text { de- } \\
\text { graded to } \\
0.865 \text { by ad- } \\
\text { dition of } \\
\text { black pig- } \\
\text { ment, found } \\
\text { from theory }\end{array}$ \\
\hline & $\begin{array}{l}\mathrm{g} / \mathrm{ft}^{2} \\
3.90 \\
4.00 \\
4.20 \\
3.50 \\
4.30\end{array}$ & $\begin{array}{l}0.674 \\
.674 \\
.683 \\
.647 \\
.657\end{array}$ & $\begin{array}{l}\mathrm{g} / \mathrm{ml} \\
1.51 \\
1.51 \\
1.51 \\
1.42 \\
1.51\end{array}$ & $\begin{array}{r}\mathrm{ml} / \mathrm{ft}^{2} \\
3.15 \\
3.25 \\
3.30 \\
3.35 \\
3.65\end{array}$ & $\begin{array}{l}0.922 \\
.916 \\
.901 \\
.876 \\
.928\end{array}$ & $\begin{array}{l}1.47 \\
1.50 \\
1.36 \\
1.43 \\
1.33\end{array}$ & $\begin{array}{l}4.92 \\
4.87 \\
4.73 \\
4.53 \\
4.99\end{array}$ & $\begin{array}{l}3.35 \\
3.25 \\
3.50 \\
3.15 \\
3.75\end{array}$ & $\begin{array}{r}\mathrm{ml} / \mathrm{ft}^{2} \\
3.05 \\
2.95 \\
3.25 \\
3.10 \\
3.35\end{array}$ \\
\hline $\begin{array}{l}e \\
\text { f } \\
\\
h \\
h\end{array}$ & $\begin{array}{l}4.50 \\
4.45 \\
4.60 \\
5.35 \\
5.50\end{array}$ & $\begin{array}{l}.676 \\
.665 \\
.676 \\
.704 \\
.682\end{array}$ & $\begin{array}{l}1.47 \\
1.48 \\
1.48 \\
1.40 \\
1.47\end{array}$ & $\begin{array}{r}3.80 \\
3.80 \\
3.80 \\
\text { 2. } 45 \\
4.55\end{array}$ & $\begin{array}{l}.904 \\
.865 \\
.912 \\
.927 \\
.906\end{array}$ & $\begin{array}{l}1.31 \\
1.22 \\
1.28 \\
1.18 \\
1.04\end{array}$ & $\begin{array}{l}\text { 4. } 76 \\
4.45 \\
4.83 \\
4.98 \\
4.78\end{array}$ & $\begin{array}{l}3.65 \\
\text { 3. } 65 \\
\text { 3. } 75 \\
4.20 \\
4.60\end{array}$ & $\begin{array}{l}3.40 \\
3.65 \\
3.45 \\
3.75 \\
4.30\end{array}$ \\
\hline
\end{tabular}

a This value is uncertain because of inconsistencies in data ascribable to unusual difficulty of spreading paint $h$ uniformly. This paint requires more water than the others for application.

A plot of contrast ratio, $C_{0.80}$, against weight of dry solids per unit area was also made for each paint, and the weight required to produce a contrast ratio of 0.93 (incomplete hiding) was read from a curve fitted graphically to the plotted points. These values are recorded in table 7 , together with the fraction, $K$, by weight of dry solids in the paste, and the density, $D$, of paint for which $K$ is adjusted to 0.5 . The values of reflectivity, $R_{\infty}$, and coefficient of scatter, $S$, recorded in table 7 are the arithmetical means of values derived from all the single coats prepared from the given paint.

\section{(d) DISCUSSION}

If the data truly followed the theory, the values of reflectivity, $R_{\infty}$, and coefficient of scatter, $S$, should be constant for each paint regardless of the thickness, $X$, of the coat. Tables 4, 5, and 6 show that there are considerable variations in reflectivity and coefficient of scatter, but since these variations, which are typical of all nine paints studied, are irregular it may be concluded that the data agree with the theory within their uncertainty. The chief source of uncertainty lies in the preparation of a uniform coat of paint so that the central areas measured by the reflectometer will be truly representative of the whole sheet.

As one criterion of the usefulness of white and near-white cold-water paint, the volume, $V$, of original paste per unit area required to produce incomplete hiding (defined as $C_{0.80}=0.93$ ) has been proposed; that is, of two paints, the one requiring a smaller volume for incomplete hiding is more economical. However, the hiding power of such paints as these can be increased by adding inexpensive black pigment, and slight additions are permissible. But to prevent excessive darkening of the paint by such additions, it is customary to specify a minimum value of reflectivity, $R_{\infty}$. On the assumption that all nine paints would meet the latter specification, the paints have been arranged in table 7 in accord with the volume, $V$, of original paste required per unit area for incomplete hiding. It will be noted that 
paints $a$ to $c$ form a group whose members are nearly equally desirable; and paints $d$ to $g$ and $h$ to $i$ form two other similar groups.

This form of specification does not rest upon any theory because reflectivity, $R_{\infty}$, may be determined directly by measurement of a coat of the paint so thick that it is completely opaque, and volume, $V$, of the original paste required per unit area for incomplete hiding may be determined as above by graphical curve fitting. It is of interest to show the relation of this specification to the constants, $R_{\infty}$ and $S$, of the Kubelka-Munk theory. The volume, $V$, per unit area required for incomplete hiding may be computed from $R_{\infty}$ and $S$ by means of the chart given in figure 2. First read $S X$ for $C_{0.80}=0.93$ corresponding to the reflectivity, $R_{\infty}$, of the paint. These values are given in the eighth column of table 7 . Then obtain $X$ for incomplete hiding by dividing $S X$ by $S$. These values are given in the ninth column of table 7. It will be noted that there is good general agreement between these values and those (fifth column) found by reading a curve fitted graphically. The same three groups having the same members appear in both columns. The cases showing poorest agreement (paints a1 and $h$ ) were examined in detail and it was found in each case that the discrepancy is well within the uncertainty of fitting the curve graphically. It is probable that the values obtained by way of the theory are somewhat more reliable because such a method amounts to fitting a curve to the data of a form which is known by extensive study to be closely correct, but in graphical curve fitting the form of the curve has to be derived anew from data obtained for each separate paint.

In addition to providing a fundamental basis for derivation of thickness for incomplete hiding, the Kubelka-Munk theory permits the comparison of paints of different reflectivity as if they had all been degraded by addition of the proper amount of black pigment to the same reflectivity value. Suppose it to be required to find for each paint the volume, $V$, of original paste needed per unit area to produce incomplete hiding after each had been degraded to a reflectivity of 0.865 . The value $S X$ corresponding to $C_{0.80}=0.93$ and to $R_{\infty}=0.865$ is read from figure 2 and found to be 4.45 . The required thickness, $X$, expressed in milliliters per square foot of original paste, is calculated as 4.45/S; values are given in the last column of table 7 . By comparison of the last two columns, it may be seen that in every case (except, of course, paint $f$, for which $R_{\infty}=0.865$ ) the volume of original paste required to produce incomplete hiding has been reduced by the addition of enough nonscattering black pigment to degrade the paint to a reflectivity of 0.865 . The effect has been to place paint $f$ in the least desirable group. This method of rating paints is thought to be the fairer of the two; it rates them in accord with coefficient of scatter, $S$.

It is concluded, therefore, that the Kubelka-Munk theory has been shown to apply within the experimental uncertainty to cold-water paints, and also that one of the constants (coefficient of scatter, $S$ ) of the theory may be taken as an index of the desirability of white coldwater paint.

\section{PAPER}

By Deane B. Judd and Merle B. Shaw

Measurements were made to determine whether the fundamental optical properties of paper also follow the Kubelka-Munk equation. 
(a) PREPARATION OF SAMPLES

Paper consists mainly of cellulose fibers felted together in a sheet. It is made by depositing, from a dilute water suspension, an even layer of fibers on a screen.

All basic papermaking materials must first be reduced to separate fibers before they can be suspended in water and formed into sheets of paper. Fibers being absorptive, sizing material is added in the preparation of the papermaking stock to make the paper more nearly impervious to ink. Dye also is added if desired. Mineral filling material is sometimes included to fill the voids between the fibers and improve the printing quality of the paper. After the admixture of fiber and nonfibrous papermaking materials (beater furnish) has reached the proper stage of preparation, sufficient water is added to give the desired consistency and the resultant stock is run onto a traveling endless wire cloth. The water drains away as the wire moves forward and the residual thin layer of fibers forms the paper. The sheet is passed over suction boxes, between press rolls and around hollow steam-heated drying cylinders to remove the water. The thickness of paper is determined by the rate of flow of stock (water with fibers in suspension) onto the wire cloth of the paper machine and by the speed of the machine.

The papers used in this study were made in the experimental paper mill of the Bureau by Merle B. Shaw and Martin J. O'Leary. The paper mill contains equipment for the experimental manufacture of practically all types of paper, under conditions which in general simulate those of industrial mills. A complete description of the equipment may be found in previous publications. ${ }^{15}$

The experimental papers were of three types - writing (two grades), book, and newsprint. Each type was of six different basis weights (designated by the letters $A$ to $F$ in table 8), all made during the same machine run from the same batch of stock, thereby precluding any differences in effects of beating, jordanning, or other processing in the preparation of the stock. Rosin size but no coloring matter was used in the papers. The following describes the papers made.

\footnotetext{
${ }^{15}$ Caroá fiber as a papermaking material, Tech. Pap. BS 21, 338-341 (1927) T340; Further experimental production of currency paper in the Bureau of Standards Paper Mill, BS J. Research 3, 904-5 (1929) RP121; Equipment and research work of the Bureau of Standards Paper Mill, Paper Trade J. 89, 19, 60-63 (1929).
} 
TABLE 8.-Detailed results for paper

Daylight reflectance, $R$, computed from the brightness ratio, $B_{\mathrm{sample}} / B_{\mathrm{MgO}}$, on the assumptions: (a) For the Priest-Lange reflectometer, $R_{\mathrm{Mg}}=0.970$; (b) For the Hunter reflectometer, $R_{\mathrm{Mg}}=1.000$

\begin{tabular}{|c|c|c|c|c|c|c|c|c|c|c|c|c|c|c|c|c|c|c|c|c|c|c|}
\hline \multirow{2}{*}{ Sample } & \multirow{2}{*}{$\begin{array}{c}\text { Ash } \\
\text { (bone- } \\
\text { dry } \\
\text { basis) }\end{array}$} & \multirow{2}{*}{$\begin{array}{c}X \\
\text { Thick- } \\
\text { ness }\end{array}$} & \multirow{2}{*}{$\begin{array}{c}X \\
w t \\
(25 \times 40 \\
\text { inches, } \\
500 \\
\text { sheets })\end{array}$} & \multicolumn{2}{|c|}{$R_{\mathrm{o}}$} & \multicolumn{2}{|c|}{$R_{\infty}$} & \multicolumn{2}{|c|}{$R_{G}$} & \multicolumn{2}{|c|}{$\begin{array}{c}C_{\infty}= \\
R_{0} / R_{\infty}\end{array}$} & \multicolumn{2}{|c|}{$\begin{array}{c}C 0.88= \\
R_{0} / R_{0.80}\end{array}$} & \multirow{2}{*}{$\begin{array}{l}\text { TAPPI } \\
\text { opacity } \\
B \& L\end{array}$} & \multicolumn{2}{|c|}{$\begin{array}{c}R_{\infty} \text { by chart } \\
\text { from } R_{0} \text { and } \\
C .089\end{array}$} & \multicolumn{2}{|c|}{$S X$} & \multicolumn{2}{|c|}{$\begin{array}{c}S \\
X=\text { thick- } \\
\text { ness }\end{array}$} & \multicolumn{2}{|c|}{$X=\stackrel{S}{=\text { weight }}$} \\
\hline & & & & $\because P-L(\mathbf{a})$ & $H(\mathbf{b})$ & $P-L$ & $H$ & $P-L$ & $H$ & $P \cdot L$ & $H$ & $P \cdot L$ & $H$ & & $P-L$ & $H$ & $P-L$ & $H$ & $P=L$ & $H$ & $P-L$ & $H$ \\
\hline $\begin{array}{c}W-A \\
B \\
C \\
D \\
E \\
F \\
F\end{array}$ & $\begin{array}{c}\text { Percent } \\
0.36 \\
.35 \\
.32 \\
.36 \\
.37 \\
.38 \\
\end{array}$ & $\begin{array}{c}\text { Inch } \\
0.0028 \\
.0033 \\
.0040 \\
.0045 \\
.0053 \\
.0082 \\
\end{array}$ & $\begin{array}{c}\text { Pounds } \\
38 \\
46 \\
53 \\
64 \\
75 \\
111 \\
\end{array}$ & $\begin{array}{r}0.691 \\
.726 \\
.754 \\
.782 \\
.805 \\
.849 \\
\end{array}$ & $\begin{array}{r}0.683 \\
.717 \\
.752 \\
.777 \\
.801 \\
.842 \\
\end{array}$ & $\begin{array}{r}0.882 \\
.887 \\
.887 \\
.885 \\
.887 \\
.889 \\
\end{array}$ & $\begin{array}{r}0.890 \\
.891 \\
.891 \\
.891 \\
.891 \\
.890 \\
\end{array}$ & $\begin{array}{r}0.881 \\
.885 \\
.883 \\
.886 \\
.884 \\
.889 \\
\end{array}$ & $\begin{array}{l}0.890 \\
.890 \\
.891 \\
.891 \\
.890 \\
.890 \\
\end{array}$ & $\begin{array}{r}0.783 \\
.819 \\
.850 \\
.884 \\
.908 \\
.955 \\
\end{array}$ & $\begin{array}{l}0.767 \\
.805 \\
.844 \\
.872 \\
.899 \\
.946\end{array}$ & $\begin{array}{r}0.782 \\
.818 \\
.852 \\
.880 \\
.909 \\
.954 \\
\end{array}$ & $\begin{array}{r}0.767 \\
.806 \\
.844 \\
.872 \\
.900 \\
.946 \\
\end{array}$ & $\begin{array}{l}0.769 \\
.802 \\
.847 \\
.872 \\
.901 \\
.950 \\
\end{array}$ & $\begin{array}{l}0.875 \\
.882 \\
.880 \\
.887 \\
.882 \\
.888\end{array}$ & $\begin{array}{r}0.890 \\
.889 \\
.891 \\
.891 \\
.890 \\
.890 \\
\end{array}$ & & & & $\begin{array}{l}800 \\
810 \\
810 \\
840 \\
850 \\
810 \\
\end{array}$ & $\begin{array}{r}0.062 \\
.061 \\
.063 \\
.062 \\
.064 \\
.065 \\
\end{array}$ & $\begin{array}{r}0.059 \\
.058 \\
.061 \\
.059 \\
.060 \\
.059 \\
\end{array}$ \\
\hline $\mathrm{Avg}_{G}$ & 0.36 & $\overline{c o n}$ & \begin{tabular}{|l}
$-\ldots . .1$ \\
$-\ldots . .$. \\
\end{tabular} & 0.885 & 0.888 & $\overline{0.886}$ & $\begin{array}{l}0.891 \\
\ldots \ldots\end{array}$ & $\overline{a . . .}$ & $\ldots$ & - & $\bar{\ldots}$ & \begin{tabular}{l}
$\ldots \ldots$ \\
\hdashline$\cdots \cdots$ \\
$-\cdots$
\end{tabular} & $\bar{\ldots}$ & מn & 0.882 & $\begin{array}{l}0.890 \\
\cdots\end{array}$ & $\begin{array}{l}\ldots \ldots \\
\ldots \ldots \\
-\ldots\end{array}$ & $\overline{-\ldots}$ & $\begin{array}{r}865 \\
-\end{array}$ & $\begin{array}{c}817 \\
\end{array}$ & 0.063 & 0.059 \\
\hline $\begin{array}{r}W-A .- \\
B- \\
C- \\
D . \\
E- \\
F=\end{array}$ & $\begin{array}{l}0.38 \\
.38 \\
.34 \\
.37 \\
.35 \\
.34 \\
\end{array}$ & $\begin{array}{l}0.0027 \\
.0031 \\
.0037 \\
.0046 \\
.00022 \\
.0081 \\
\end{array}$ & $\begin{array}{r}38 \\
46 \\
52 \\
64 \\
76 \\
118 \\
\end{array}$ & $\begin{array}{r}0.614 \\
.656 \\
.688 \\
.724 \\
.746 \\
.789 \\
\end{array}$ & $\begin{array}{r}\overline{0.606} \\
.646 \\
.677 \\
.717 \\
.740 \\
.778 \\
\end{array}$ & $\begin{array}{r}.820 \\
.818 \\
.821 \\
.821 \\
.822 \\
.820 \\
\end{array}$ & $\begin{array}{r}.811 \\
.809 \\
.815 \\
.814 \\
.817 \\
.811 \\
\end{array}$ & $\begin{array}{l}\overline{0.848} \\
.845 \\
.841 \\
.841 \\
.837 \\
.829 \\
\end{array}$ & $\begin{array}{r}.848 \\
.841 \\
.839 \\
.834 \\
.833 \\
.820 \\
\end{array}$ & $\begin{array}{r}.749 \\
.802 \\
.838 \\
.882 \\
.908 \\
.962 \\
\end{array}$ & $\begin{array}{r}0.747 \\
.799 \\
.831 \\
.881 \\
.906 \\
.959 \\
\end{array}$ & $\begin{array}{r}\overline{0.719} \\
.772 \\
.813 \\
.858 \\
.888 \\
.950 \\
\end{array}$ & $\begin{array}{r}.715 \\
.768 \\
.807 \\
.860 \\
.888 \\
.949 \\
\end{array}$ & $\begin{array}{r}0.712 \\
.768 \\
.807 \\
.862 \\
.887 \\
.944 \\
\end{array}$ & $\begin{array}{r}0.811 \\
.814 \\
.817 \\
.820 \\
.820 \\
.821 \\
\end{array}$ & $\begin{array}{r}0.800 \\
.801 \\
.805 \\
.808 \\
.813 \\
.810 \\
\end{array}$ & $\begin{array}{l}1.72 \\
2.11 \\
2.50 \\
3.11 \\
3.63 \\
5.50 \\
\end{array}$ & & $\begin{array}{l}640 \\
680 \\
680 \\
680 \\
700 \\
680 \\
\end{array}$ & $\begin{array}{l}620 \\
660 \\
650 \\
670 \\
690 \\
650 \\
\end{array}$ & $\begin{array}{r}\overline{0.045} \\
.046 \\
.048 \\
.049 \\
.048 \\
.047 \\
\end{array}$ & $\begin{array}{l}0.044 \\
.044 \\
.046 \\
.048 \\
.047 \\
.045 \\
\end{array}$ \\
\hline $\mathrm{vg}_{-}$ & 0.36 & & & 0.880 & 0.888 & $\overline{.820}$ & 0.813 & & & & & & & & 0.817 & $\overline{0.806}$ & & & 677 & $\begin{array}{c}657 \\
\end{array}$ & $\overline{0.047}$ & 0.046 \\
\hline $\begin{array}{l}C \ldots \\
D-. \\
E-. \\
F \ldots\end{array}$ & $\begin{array}{l}5.80 \\
5.81 \\
5.76 \\
5.82 \\
5.93 \\
6.22 \\
\end{array}$ & $\begin{array}{l}.0030 \\
.0035 \\
.0041 \\
.0048 \\
.0059 \\
.0103 \\
\end{array}$ & $\begin{array}{r}39.1 \\
46.0 \\
53.9 \\
62.5 \\
76.0 \\
129.5 \\
\end{array}$ & $\begin{array}{r}0.730 \\
.750 \\
.772 \\
.785 \\
.804 \\
.825 \\
\end{array}$ & $\begin{array}{l}0.725 \\
.745 \\
.769 \\
.785 \\
.802 \\
.821 \\
\end{array}$ & $\begin{array}{r}0.831 \\
.832 \\
.829 \\
.831 \\
.830 \\
.829 \\
\end{array}$ & $\begin{array}{l}.827 \\
.828 \\
.828 \\
.829 \\
.826 \\
\end{array}$ & $\begin{array}{r}.844 \\
.847 \\
.837 \\
.839 \\
.833 \\
.829 \\
\end{array}$ & $\begin{array}{l}.845 \\
.843 \\
.839 \\
.838 \\
.836 \\
\end{array}$ & $\begin{array}{r}.878 \\
.902 \\
.931 \\
.945 \\
.969 \\
.995 \\
\end{array}$ & $\begin{array}{r}0.877 \\
.900 \\
.929 \\
.947 \\
.966 \\
.994 \\
\end{array}$ & $\begin{array}{r}0.862 \\
.883 \\
.920 \\
.933 \\
.964 \\
.995 \\
\end{array}$ & $\begin{array}{l}0.858 \\
.884 \\
.917 \\
.937 \\
.959 \\
.992 \\
\end{array}$ & $\begin{array}{l}0.85 \\
.88 \\
.91 \\
.93 \\
.95 \\
.99\end{array}$ & $\begin{array}{l}.825 \\
.831 \\
.825 \\
.830 \\
.828 \\
\end{array}$ & $\begin{array}{l}.822 \\
.822 \\
.825 \\
.827 \\
.829 \\
.827\end{array}$ & \begin{tabular}{|c|}
3.19 \\
3.61 \\
4.48 \\
4.95 \\
6.45 \\
11.3 \\
\end{tabular} & \begin{tabular}{|c|}
3.12 \\
3.58 \\
4.36 \\
5.05 \\
6.2 \\
10.2 \\
\end{tabular} & & \begin{tabular}{r|}
1040 \\
1020 \\
1060 \\
1050 \\
1050 \\
990 \\
\end{tabular} & $\begin{array}{l}.080 \\
.078 \\
.083 \\
.078 \\
.085 \\
.087 \\
\end{array}$ & $\begin{array}{l}0.082 \\
.078 \\
.081 \\
.081 \\
.082 \\
.079 \\
\end{array}$ \\
\hline$v_{G}$ & 5.89 & & & 0.880 & 0.888 & 0.830 & 0.828 & & & & & $=\ldots$ & & 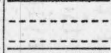 & 0.830 & 0.825 & & $\ldots$ & $\begin{array}{r}1063 \\
\end{array}$ & $\begin{array}{c}1043 \\
- \\
\end{array}$ & 0.082 & 0.080 \\
\hline $\begin{array}{c}T-A \\
B-. \\
C-. \\
D- \\
E-. \\
F-.\end{array}$ & $\begin{array}{l}0.39 \\
.38 \\
.38 \\
.39 \\
.39 \\
.39 \\
\end{array}$ & $\begin{array}{l}.0040 \\
.0046 \\
.0056 \\
.0064 \\
.0075 \\
.0132 \\
\end{array}$ & $\begin{array}{r}37 \\
43 \\
53 \\
64 \\
75 \\
122 \\
\end{array}$ & $\begin{array}{r}0.603 \\
.607 \\
.616 \\
.624 \\
\\
\end{array}$ & $\begin{array}{r}\overline{0.593} \\
.598 \\
.605 \\
.610 \\
.604 \\
.598 \\
\end{array}$ & \begin{tabular}{r}
0.623 \\
.621 \\
.624 \\
.624 \\
\hdashline..- \\
\end{tabular} & $\begin{array}{r}.611 \\
.608 \\
.610 \\
.612 \\
.605 \\
.598 \\
\end{array}$ & \begin{tabular}{r}
.638 \\
.629 \\
.627 \\
.625 \\
\hdashline..- \\
\end{tabular} & $\begin{array}{l}.626 \\
.617 \\
.614 \\
.613 \\
.606 \\
.598 \\
\end{array}$ & $\begin{array}{r}\overline{0.968} \\
.978 \\
.987 \\
1.000\end{array}$ & $\begin{array}{r}.984 \\
.992 \\
.997 \\
.998 \\
1.000\end{array}$ & $=\mid$\begin{tabular}{r}
$\overline{0.945}$ \\
.965 \\
.982 \\
.998 \\
\hdashline... \\
..... \\
\end{tabular} & $\begin{array}{r}0.947 \\
.969 \\
.985 \\
.995 \\
.997 \\
1.000\end{array}$ & $\begin{array}{r}0.93 \\
.95 \\
.98 \\
.99 \\
.99 \\
1.00 \\
\end{array}$ & \begin{tabular}{c}
.621 \\
.618 \\
.621 \\
.625 \\
\hdashline \\
\hdashline
\end{tabular} & $\begin{array}{r}\overline{0.609} \\
.608 \\
.609 \\
.612 \\
.605 \\
.598 \\
\end{array}$ & $\begin{array}{l}3.10 \\
3.52 \\
4.23 \\
6.5 \\
-.-. \\
\end{array}$ & \begin{tabular}{|l|}
3.53 \\
3.56 \\
4.28 \\
5.6 \\
6.7 \\
$\infty$ \\
\end{tabular} & $\begin{array}{c}780 \\
770 \\
760 \\
-0 \\
-0 \\
\end{array}$ & $\begin{array}{l}760 \\
770 \\
760 \\
900 ? \\
900 ? \\
\infty ?\end{array}$ & \begin{tabular}{c}
0.084 \\
.082 \\
.080 \\
$.1 ?$ \\
\hdashline \\
\end{tabular} & $\begin{array}{l}0.082 \\
.083 \\
.081 \\
.09 ? \\
.09 ? \\
\infty ?\end{array}$ \\
\hline$v_{G}$ & 0.39 & 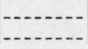 & ... & 0.888 & 0.888 & $\begin{array}{c}.623 \\
-\end{array}$ & 0.607 & $-\ldots . .$. & ..... & $\cdots$ & $\cdots$ & - & $\ldots$ & 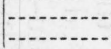 & 0.621 & $-\begin{array}{l}0.607 \\
-\ldots .--\end{array}$ & $\ldots$. & $\ldots$ & 770 & $\begin{array}{c}747 \\
\cdots\end{array}$ & 0.082 & 0.082 \\
\hline
\end{tabular}


(1) Writing Papers.-Writing paper was made from sulphite pulp (designated $S W$ in table 8 ) and from rag half stuff that had been bleached to very good white color (designated $R W$ in table 8). 1.5 percent of rosin size was added in each. No filler or dye was used.

(2) Book Paper.-The book paper (designated B in table 8) contained clay because the beater furnish was paper-machine "broke" (trimmings or torn paper) from previous runs of book papers in which clay had been used. 1.5 to 2 percent of rosin size, based on weight of dry fiber, was added. Data on weight, thickness, and ash for each basis weight of the paper made are given in table 8 .

(3) Newsprint Paper. - The beater furnish for this run (designated $N$ in table 8) was newsprint taken from a roll of commercial newsprint paper. For this run only 0.5 percent of size was used.

It was found impossible to obtain the same finish on the heavy papers, designated $E$ and $F$ in the table, as was obtained on the lighter-weight papers because of the smallness of the calendar stack. The heavier papers, especially sample $F$, seemed "two-sided." The smoother side was the under- or wire-side; the other side was marked by the couch-roll jacket.

\section{(b) MEASUREMENTS}

Measurements of reflectance were made on the Hunter "photox photoelectric" reflectometer and on the Priest-Lange reflectometer. Five samples of each paper were tested, the Hunter reflectometer giving average apparent reflectance over a nearly circular area about $7 \mathrm{~cm}$ in diameter, the Priest-Lange reflectometer over a semicircular area of about $1 \mathrm{~cm}$ diameter near the center of the sample. The backings used for these measurements were (1) black velvet for which $R^{\prime}$ was taken equal to zero; (2) an opaque stack of the paper itself for which $R^{\prime}$ was taken equal to $R_{\infty}$; and (3) a backing designated as $G$ which consisted of an opaque stack of rag writing paper $\left(R W-F^{\prime}\right)$ for which $R^{\prime}$ varied from 0.888 to 0.880 because of slight soiling during use. The results of these measurements by the two reflectometers are given in table 8 in parallel columns, the Priest-Lange reflectometer being designated by the letters $P-L$, and the Hunter reflectometer being designated by the letter $H$.

Both of these reflectometers measure apparent reflectance, $A$, relative to magnesium oxide, the Priest-Lange reflectometer illuminating the sample and standard nearly diffusely and viewing them perpendicularly, the Hunter reflectometer illuminating them nearly perpendicularly and viewing them at nearly $45^{\circ}$. The estimated values of reflectance, $R$, given in table 8 for the nearly mat paper samples were found from the Priest-Lange values as $0.97 A / A_{\mathrm{MgO}}$, and from the Hunter values as simply $A / A_{\mathrm{MgO}}$. These estimates are based on the values of $A_{\mathrm{MgO}}$ for the respective angular conditions; that is, for the conditions of the Hunter reflectometer $A_{\mathrm{MgO}}=1.00 .^{16}$ The estimates are also based on the assumption, known not to be strictly justified, that the paper samples are perfect diffusers, that is, that the light reflected from them is distributed equally in all directions.

Both the Priest-Lange reflectometer readings and those by the Hunter reflectometer are characteristic of observation of the samples

16 J. S. Preston, The reflection of magnesium oxide, Trans. Opt. Soc. 31, 15 (1929-30).

H. J. McNicholas, Absolute methods in reflectometry, BS J. Research 1, 29 (1928). RP3.

Preparation and Colorimetric Properties of a Magnesium-Oxide Reflectance Standard, NBS Letter Circular LC395. 
in daylight by a normal human observer. With the Priest-Lange reflectometer, a visual instrument, this effect was obtained by using a sunlight filter; with the Hunter reflectometer, although the illuminant was a gas-filled lamp, approximately this effect is obtained because the spectral sensitivity of the Photox cell is relatively somewhat higher for the short-wave part of the spectrum than the spectral luminosity curve for the average eye.

There are also shown in table 8 values of TAPPI opacity for these papers obtained from a photoelectric opacimeter designed by M. N. Davis. ${ }^{17}$ In this opacimeter the sample is illuminated nearly perpendicularly by incandescent-lamp light and is viewed diffusely by means of an integrating cube and photronic cell.

\section{(c) REDUCTION OF DATA}

Entries in the column headed, $C_{\infty}=R_{0} / R_{\infty}$, of table 8 were obtained by simple division of values of $R_{0}$ by $R_{\infty}$. This ratio for paper has been used considerably under the name of printing opacity.

Entries in the column headed $C_{0.89}=R_{0} / R_{0.89}$ were computed from $R_{0}$ and $R_{G}$. This computation would have been simple division provided sample $G$ had turned out to have a reflectance of exactly 0.89 . Since, however, in some cases the reflectance of sample $G$ departed by as much as 0.01 from 0.89 , corrections read from figure 5 were applied. As an example of the way to apply these corrections take sulphite writing paper of the least thickness $(S W-A)$. The reflectance over a black backing, $R_{0}$, is estimated from the results by the Priest-Lange reflectometer as 0.614 (see table 8 ); that over backing $G$, as 0.848 . The ratio, $R_{0} / R_{G}$, is 0.724 , and since backing $G$ had a reflectance during this reading of 0.880 , this result could be written: $C_{0.88}=0.724$. To find $C_{0.89}$ for this sample refer to figure 5 (upper plot). For $C_{0.90}$ in the neighborhood of 0.72 and for $R_{0}$ about 0.61 , the value of the correction, $C_{0.80}-C_{0.90}$, for a deviation of $R^{\prime}$ of 0.10 is seen to be about 0.047 . Since this case yields a deviation in $R^{\prime}$ of only 0.01 , the correction is taken as one-tenth the value read from figure 5, that is, the correction to be applied is 0.005 . The value of $C_{0.89}$ is, therefore, $0.724-0.005=0.719$.

Values of $R_{\infty}$ and $S X$ were read from $R_{0}$ and $C_{0.89}$ by means of figure 1. From the values of $S X, S$ was computed both for $X$ taken as basis weight in pounds per 500 sheets of 25 by 40 inches and $X$ taken as thickness in inches.

\section{(d) DISCUSSION}

It may be noted that for the writing paper and the newsprint paper estimates of reflectance from readings of the Priest-Lange reflectometer tend to be higher by about 1 percent than those from readings of the Hunter reflectometer. For the book paper the difference is in the same sense but considerably less. The data from the two instruments have been reduced separately so that the amount of the differences may be traced through to the end. These differences are evidently related to angular distribution of the reflected light; and, in fact, for some other materials the differences are in the opposite direction.

Values of $C_{0.89}$, since they refer to daylight as illuminant, are not quite comparable with those of TAPPI opacity obtained by the Davis

${ }_{17}$ See footnote 11, p. 295. 
(B \& L) opacimeter, which refer to incandescent-lamp light. The yellower light from the incandescent lamp is expected to penetrate paper more readily because both absorption and scattering coefficients of these papers are lower for long-wave light, and this greater penetration results in values of TAPPI opacity somewhat lower than those of $C_{0.89}$, obtained from the Priest-Lange reflectometer. The angular conditions of illuminating and viewing for these two instruments are nearly reciprocal; hence, they would be expected to yield comparable

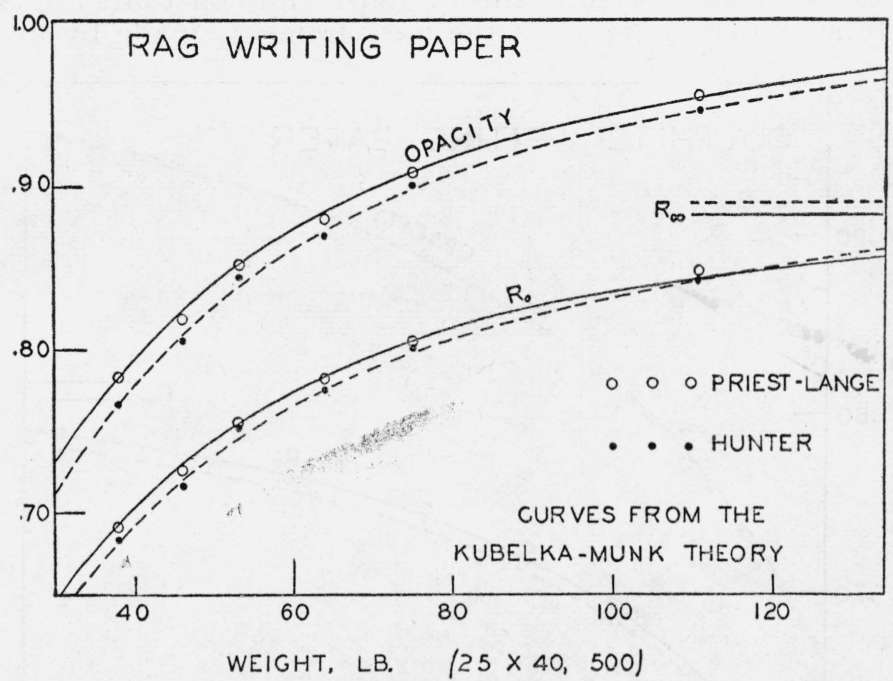

Figure 10.-Rise in opacity, $C_{0.89}$ (upper curve) and reflectance, $R_{0}$, (lower curve) of rag writing paper with basis weight.

The plotted points are estimates based on measured values of apparent reflectance $A_{0}$; the curves are from the Kubelka-Munk theory.

results were it not for the difference in spectral energy distribution of illuminant. The Hunter reflectometer on the other hand uses both unidirectional illumination and unidirectional viewing; so it would not be expected to yield results exactly comparable to the other two instruments, which use either diffuse illumination or diffuse viewing. It is of interest, however, to note that $C_{0.89}$ by the Hunter reflectometer is in good agreement with TAPPI opacity. This suggests that for these papers the disparity in spectral distribution of illuminant and receptor sensitivity has by a coincidence been closely compensated for by the difference in angular distribution.

The agreement between the observed reflectivities, $R_{\infty}$, and those obtained from the chart is good, the differences in all but two or three cases being less than the uncertainty of the experimental results. There is a significant tendency, however, exhibited in most of the results, for reflectivity estimated by the chart (fig. 1) based on the Kubelka-Munk theory to be lower than that directly measured, the thinner papers showing the greater discrepancy. It is concluded, therefore, that the Kubelka-Munk theory does not apply strictly to papers measured in the usual way with these reflectometers. The causes for the slight discrepancies are not known definitely.

The coefficients of scatter show a similar tendency to be slightly lower for the lower thicknesses of paper, although this tendency is of 
doubtful significance for the book papers. A possible explanation of the tendency of both reflectivity and coefficient of scatter to be low for thin samples of the nonweighted papers is that the water in draining out of the thin samples carried away disproportionately large numbers of fine white particles compared to thicker samples.

The degree of agreement between the measurements and the Kubelka-Munk theory is also shown in figures 10, 11, and 12 . The plotted points represent the results of measurement; the solid curves represent the Kubelka-Munk theory (eq 1) for constants adjusted to fit nearly as closely as possible the measurements made by means of

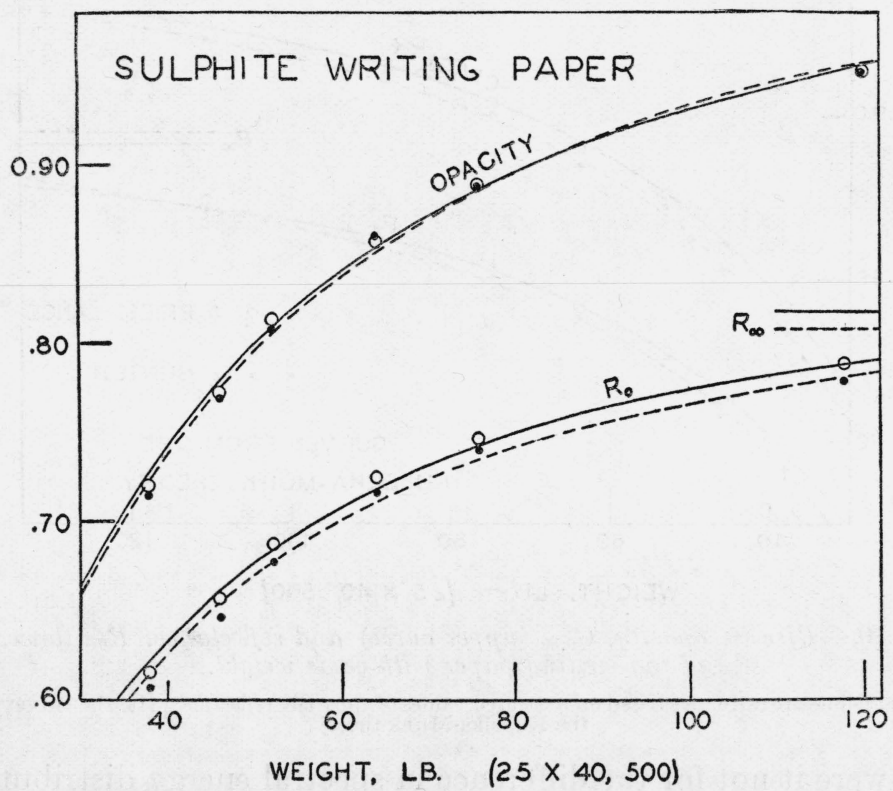

Figure 11.-Rise in opacity, $C_{0.89}$ (upper curve) and reflectance, $R_{0}$ (lower curve) of sulphile writing paper with basis weight.

The plotted points are estimates based on measured values of apparent reflectance, $A_{0}$; the curves are from the Kubelka-Munk theory.

the Priest-Lange refiectometer; the dotted curves similarly represent the theory fitted to the measurements made by the Hunter reflectometer. These graphs show the measured rise in reflectance over black backing, $R_{0}$, and the measured rise in opacity compared to the respective theoretical variations. The small but significant deviations from the theory are evident as is also the rather closer fit to theory obtained with the rag writing and book papers. Results for the newsprint papers are omitted because of the restricted range in opacity obtained.

It is concluded that, except for deviations of less than 1 percent, the Kubelka-Munk theory applies to paper; the two constants of the theory, reflectivity, $R_{\infty}$, and coefficient of scatter, $S$, yield a useful description of the material of which paper is made. This holds both for $X$, as thickness and for $X$ as basis weight. By means of a description in these terms the optical properties of the papers made from the four types of furnishes studied may be predicted within 1 percent 
over the whole practical range of basis weights. The constants may also be correlated with the appearance and composition of the paper.

Table 9 gives a summary of the average characteristics determined from the Hunter reflectometer for the four types of paper studied. Average values of ash are also included.

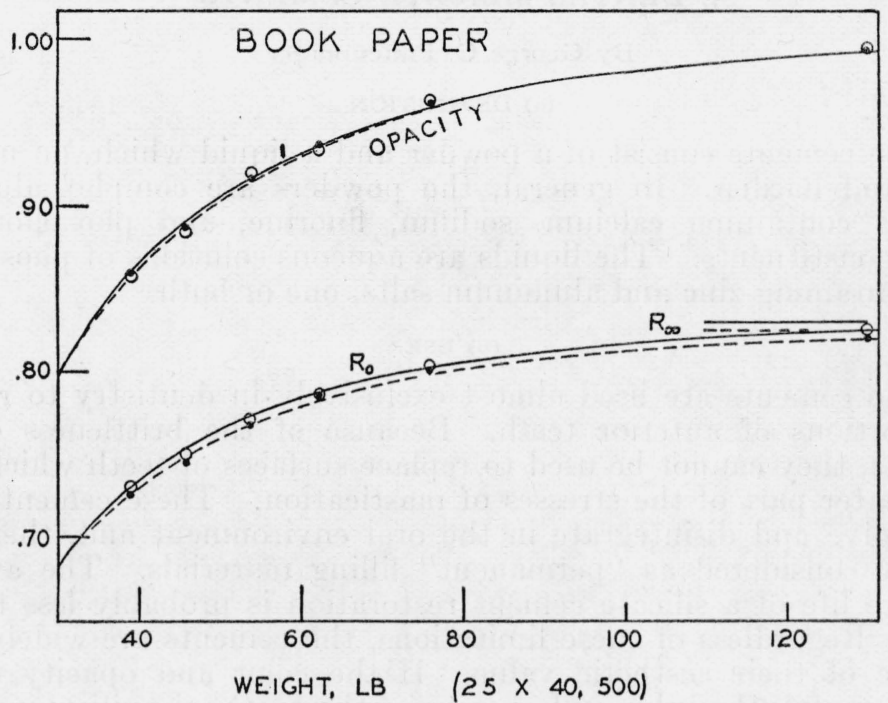

Figure 12.-Rise in opacity, $C_{0.89}$ (upper curve) and reflectance, $R_{0}$ (lower curve) of book paper with basis weight.

The plotted points are estimates based on measured values of apparent reflectance, $A_{0}$; the curves are from the Kubelka-Munk theory.

TABLE 9.-Summary for paper

\begin{tabular}{|c|c|c|c|c|}
\hline \multirow{2}{*}{ Type of paper } & \multirow{2}{*}{$\begin{array}{l}\text { Reflectivity, } \\
R_{\infty}\end{array}$} & \multicolumn{2}{|c|}{ Coefficient of scatter, $S$} & \multirow{2}{*}{ Ash } \\
\hline & & Per inch & Per pound & \\
\hline $\begin{array}{l}\text { Rag writing } \\
\text { Sulphite writing } \\
\text { Book } \\
\text { Newsprint. }\end{array}$ & $\begin{array}{r}0.89 \\
.81 \\
.83 \\
.61\end{array}$ & $\begin{array}{r}820 \\
660 \\
1,040 \\
750\end{array}$ & $\begin{array}{l}0.059 \\
.046 \\
.080 \\
.080\end{array}$ & $\begin{array}{r}0.36 \\
.36 \\
5.89 \\
0.39\end{array}$ \\
\hline
\end{tabular}

Reflectivity is seen to be highest for the rag-writing paper and lowest for the newsprint paper; it correlates with usefulness of the paper to form a background for legible dark letters and it also correlates with the cost of the paper..$^{18}$ Coefficient of scatter expressed per unit basis weight is lowest for sulphite writing paper and highest for the book and the newsprint. The increased coefficient of scatter for the book paper over the rag writing paper may be ascribed to the presence of clay filler (note high ash); that for newsprint paper may be ascribed to the presence of groundwood. Coefficient of scatter expressed per unit thickness is also lowest for the sulphite writing paper, but that for the newsprint paper is in this case considerably

18 A better index of cost than daylight reflectivity is reflectivity for blue light (often called "brightness") See L. C. Lewis, Definition of brightness, Paper Trade J. 101, no. 6, TS64 (August 8, 1935); Recent progress on color problems in the paper industry, Paper Trade J. 103, no. 22, TS323 (November 26, 1936). 
lower than that for the book paper. This corresponds to the greater bulk of the newsprint paper.

This general applicability of the Kubelka-Munk theory to paper is in agreement with the less detailed reports by Steele ${ }^{19}$ and Lewis. ${ }^{20}$

\section{DENTAL SILICATE CEMENTS ${ }^{21}$}

\section{By George C. Paffenbarger}

(a) DEFINITION

These cements consist of a powder and a liquid which, on mixing, react and harden. In general, the powders are complex aluminosilicates containing calcium, sodium, fluorine, and phosphorus as major constituents. The liquids are aqueous solutions of phosphoric acid containing zinc and aluminum salts, one or both.

\section{(b) USE}

These cements are used almost exclusively in dentistry to replace lost portions of anterior teeth. Because of the brittleness of the cements, they cannot be used to replace surfaces of teeth which bear the greater part of the stresses of mastication. These cements tend to dissolve and disintegrate in the oral environment and, therefore, are not considered as "permanent" filling materials. The average effective life of a silicate cement restoration is probably less than 3 years. Regardless of these limitations, the cements are widely used because of their aesthetic value. If the color and opacity of the cement match the color and opacity of the tooth, the silicate cement restoration blends with the tooth structure and is difficult to detect. Thus, the opacity is a very important element in the evaluation of the cement.

\section{(c) PREPARATION OF SPECIMENS}

The cements were mixed on a glass slab with an agate spatula by the common dental method. Disks of the cement were formed by pressing the plastic cement between two flat glass plates which were separated by gage blocks of the desired thickness. After the initial hardening had occurred the specimen was immersed in distilled water and was kept under water at all times to prevent deterioration.

\section{(d) METHOD OF MEASUREMENT}

Measurements of reflectance of the cement specimens covered with water were made on a Priest-Lange reflectometer. Because the specimen could be brought into focus in the photometric field of this instrument, thus permitting comparisons of different parts of the specimen, it was possible to use specimens of a minimum area. Furthermore, the reflectance of small sections of human enamel and dentin could be determined with this instrument. Until the opacity of tooth tissue could be determined, it was difficult to establish rational opacity requirements for the silicate cements.

\footnotetext{
$10 \mathrm{~F}$. A. Steele, The optical characteristics of paper. I. The mathematical relationships between basis weight, reflectance, contrast ratio, and other optical properties, Paper Trade J. 100, no. 12, 37 (March 21, 1935).

$20 \mathrm{~L}$. C. Lewis, Recent progress on color problems in the paper industry, Paper Trade J. 103, no. 22, TS323 (November 26, 1936).

${ }_{21}$ Geo. C. Paffenbarger, and Irl C. Schoonover, Physical properties of dental silicate cements (abstract), J. Dental Research 15, 322 (September 1936). For a detailed report, see Paffenbarger, Geo. C., Schoonover, Irl C., and Souder, Wilmer, Silicate cements, physical and chemical properties, and a specification. To be published in volume 24 (1937) of the J. American Dental Association.
} 
Because the reflectance of a substance is in general a function of the wave length of the incident light and because, in ordinary conditions of use of dental cements, daylight is the incident light, a "daylight" filter was employed. The reflectances and contrast ratios given in this section of the report are, therefore, for artificial noon sunlight.

A hardened specimen of cement consists of numerous particles of powder (many of which are undoubtedly only superficially attacked by the liquid) bound together by the matrix of cementing substance. It was estimated that the powder particles amount to from 70 to 80 percent and the matrix from 20 to 30 percent of the hardened cement. The indices of refraction of the powder particles, which are almost all isotropic, ranged from 1.47 to $1.60 .^{22}$ The indices of the matrix varied from 1.45 to 1.48 . An appreciable amount of air is trapped in the cement during mixing. The effect of multiple reflections of the air-water interface and the cement-water interface caused by the difference in the indices of refraction of these media was neglected because the computed corrections were too small to affect the results significantly.

(e) DISCUSSION OF DATA

Three cements having different opacities were selected. The $C_{.70}$ values of $1 \mathrm{~mm}$-thick specimens of these cements were: Cement $F$ (white), 1.00 ; cement $D$ (light yellowish gray), 0.43 ; cement $D$ (light yellow), 0.41 ; cement $K$ (dark gray), 0.32 ; cement $K$ (white), 0.24 . White and dark gray are the lightest and darkest shades, respectively, which are in common use.

The $R_{\infty}$ and $S$ values obtained from figure 3 for these cements were not as concordant as for the other materials tested. These variations are too great to be ascribed to photometric uncertainty, and the data on cement $K$ (white) suggest that variations among $R_{\infty}$ and $S$ values may be caused by inhomogeneities among specimens. In preparing the larger specimens, mixes 100 times larger than those used in ordinary dental operations, were necessary. This made it difficult to disperse the powder particles and the trapped air bubbles evenly before the cement began to set.

The constants $R_{\infty}$ and $S$ can be correlated with the composition of the cements. For example, cement $F$, the powder of which contains over 50 percent of zinc oxide, has the highest coefficient of scatter, $S$. Cements $D$ and $K$ are similar in chemical composition but their respective powder particles have a different physical structure. Petrographic analysis revealed that the powder particles of cement $D$ were cloudy, while those of cement $K$ were clear. This distinction correlates with the higher $S$ value of cement $D$. Note also that the reflectivities, $R_{\infty}$, of cements $K$, white and gray, are high and low, respectively, while the $S$ values are approximately the same. A possible interpretation is that the dark-gray cement was produced by adding a nonscattering black pigment to the white cement.

The data (table 10) indicate that the formula of Kubelka and Munk is applicable to dental silicate cements within the rather large uncertainty involved in the preparation of specimens.

${ }^{22}$ Petrographic examinations were made by $\mathrm{H}$. Inslev. 
TABLE 10.-Reflectance data for silicate cements

\begin{tabular}{|c|c|c|c|c|c|c|c|}
\hline \multicolumn{2}{|r|}{ Cement 1} & \multirow{2}{*}{$x$} & \multirow{2}{*}{$R_{0}$} & \multirow{2}{*}{$C_{0.70}$} & \multirow{2}{*}{$R_{\infty}$} & \multirow{2}{*}{$S X$} & \multirow{2}{*}{$S$} \\
\hline Code letter & Color & & & & & & \\
\hline & 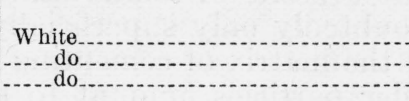 & $\begin{array}{c}\mathrm{mm} \\
0.37 \\
.58 \\
.82\end{array}$ & $\begin{array}{r}0.649 \\
.713 \\
.722\end{array}$ & $\begin{array}{r}0.874 \\
.952 \\
.980\end{array}$ & $\begin{array}{r}0.76 \\
.76 \\
.74\end{array}$ & $\begin{array}{l}2.25 \\
3.69 \\
5.00\end{array}$ & $\begin{array}{r}0.61 \\
.64 \\
.61\end{array}$ \\
\hline $\begin{array}{l}F^{2} \\
F^{2}-1 \\
F^{2}\end{array}$ & -do do & $\begin{array}{l}.37 \\
.58 \\
.82\end{array}$ & $\begin{array}{l}.653 \\
.720 \\
.737\end{array}$ & $\begin{array}{r}.870 \\
.950 \\
1.000\end{array}$ & $\begin{array}{l}.77 \\
.77 \\
.74\end{array}$ & $\begin{array}{l}\text { 2. } 23 \\
3.70 \\
\text { (3) }\end{array}$ & $\begin{array}{l}.60 \\
.64\end{array}$ \\
\hline$D$. & 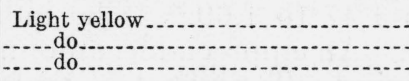 & $\begin{array}{r}.52 \\
.85 \\
1.06\end{array}$ & $\begin{array}{l}.145 \\
.224 \\
.262\end{array}$ & $\begin{array}{l}.218 \\
.356 \\
.434\end{array}$ & $\begin{array}{l}.50 \\
.50 \\
.49\end{array}$ & $\begin{array}{l}.178 \\
.317 \\
.405\end{array}$ & $\begin{array}{l}.34 \\
.37 \\
.38\end{array}$ \\
\hline $\begin{array}{l}D \ldots . . \\
D \\
D \ldots . . .\end{array}$ & \begin{tabular}{l} 
Light yellowish-gray \\
\hdashline do
\end{tabular} & $\begin{array}{r}.50 \\
.82 \\
1.14\end{array}$ & $\begin{array}{l}.141 \\
.207 \\
.274\end{array}$ & $\begin{array}{l}.234 \\
.370 \\
.502\end{array}$ & $\begin{array}{l}.40 \\
.40 \\
.43\end{array}$ & $\begin{array}{l}.184 \\
.304 \\
.468\end{array}$ & $\begin{array}{l}.37 \\
.37 \\
.41\end{array}$ \\
\hline $\begin{array}{l}K \\
K \\
K \\
K\end{array}$ & $\begin{array}{l}\text { White } \\
\text { do- }\end{array}$ & $\begin{array}{l}2.10 \\
3.03 \\
4.75\end{array}$ & $\begin{array}{l}.291 \\
.326 \\
.481\end{array}$ & $\begin{array}{l}.440 \\
.575 \\
.786\end{array}$ & $\begin{array}{l}.60 \\
.48 \\
.58\end{array}$ & $\begin{array}{l}.442 \\
.610 \\
1.2\end{array}$ & $\begin{array}{l}.21 \\
.20 \\
.26\end{array}$ \\
\hline $\begin{array}{ll}K^{4} \\
K^{4}-\ldots+\cdots \\
K^{4}\end{array}$ & $\begin{array}{c}\text { do } \\
\text { do }\end{array}$ & $\begin{array}{l}2.10 \\
\text { 3. } 03 \\
4.75\end{array}$ & $\begin{array}{l}.261 \\
.309 \\
.431\end{array}$ & $\begin{array}{l}.395 \\
.543 \\
.708\end{array}$ & $\begin{array}{l}.59 \\
.47 \\
.56\end{array}$ & $\begin{array}{l}.375 \\
.545 \\
.970\end{array}$ & $\begin{array}{l}.18 \\
.18 \\
.20\end{array}$ \\
\hline$K^{K} \mathrm{~s}$ & do & $\begin{array}{l}2.02 \\
3.26 \\
4.96\end{array}$ & $\begin{array}{l}.265 \\
.368 \\
.486\end{array}$ & $\begin{array}{l}.390 \\
.586 \\
.784\end{array}$ & $\begin{array}{l}.63 \\
.57 \\
.59\end{array}$ & $\begin{array}{r}.380 \\
.683 \\
1.27\end{array}$ & $\begin{array}{l}.19 \\
.21 \\
.26\end{array}$ \\
\hline$\gamma^{6}-\ldots$ & do do & $\begin{array}{l}2.00 \\
3.28\end{array}$ & $\begin{array}{l}.262 \\
.437\end{array}$ & $\begin{array}{l}.390 \\
.660\end{array}$ & $\begin{array}{l}.62 \\
.63\end{array}$ & $\begin{array}{l}.370 \\
.900\end{array}$ & $\begin{array}{l}.19 \\
.27\end{array}$ \\
\hline $\begin{array}{l}K \\
K \\
K \\
K\end{array}$ & $\begin{array}{l}\text { Dark gray } \\
\quad \text { do } \\
\text { do }\end{array}$ & $\begin{array}{l}1.95 \\
\text { 3. } 04 \\
4.72\end{array}$ & $\begin{array}{l}.137 \\
.152 \\
.153\end{array}$ & $\begin{array}{l}.639 \\
.880 \\
.940\end{array}$ & $\begin{array}{l}.16 \\
.16 \\
.16\end{array}$ & $\begin{array}{l}.351 \\
.566 \\
.700\end{array}$ & $\begin{array}{l}.18 \\
.19 \\
.15\end{array}$ \\
\hline
\end{tabular}

1 Specimens were 1-week old, except where noted.

2 Same as $F$ except specimens were 18 days old.

3 Could not read on plot (fig. 3 ).

1 Same as $K$ (white), except specimens were 18 days old.

o 6 Additional 1-week-old specimens of $K$ (white).

\section{SUMMARY}

It is concluded that the simple Kubelka-Munk theory applies to reflectance measurements of vitreous enamel, cold-water paint, paper, and dental silicate cements, made on the usual reflectometers in the usual ways. Either no regular deviations of theory from actual measurement are found, or the deviations found are of about the order of magnitude of the experimental uncertainty. It will be noted that the agreement between theory and experiment is as good for materials whose medium differs from air (vitreous enamel and dental silicate cement) as it is for materials having air as the medium (paper and cold-water paint). It would seem, therefore, that corrections for light reflected from the inner side of the air-medium face are negligible. Description of these materials by means of the two constants of the theory, reflectivity and coefficient of scatter, is, therefore, of practical validity and use. The most valuable use of the methods described herein is to differentiate in a fundamental way between various members of the same group of materials. Such differentiations are illustrated in tables 1 and 2 (vitreous enamels); 4, 5, 6, and 7 (cold-water paints); 8 and 9 (papers); and 10 (dental silicate cements). These methods also permit comparisons to be made between different classes of materials. Such comparisons are 
shown in table 11 in which the coefficient of scatter refers to thickness expressed in microns for all materials. It will be noted that materials whose scattering elements are distributed in air (cold-water paint, paper) have higher coefficients of scatter. Note also that vitreous enamels have a much higher coefficient of scatter than dental silicate cements; this corresponds to the different purposes of the two materials, the one to hide the ground coat with as thin a layer as possible, the other to match fairly translucent tooth enamel.

TABLE 11.-Summary

\begin{tabular}{l|l|l}
\hline Material & $\begin{array}{c}\text { Reflectivity, } \\
R_{\infty}\end{array}$ & $\begin{array}{c}\text { Coefficient } \\
\text { of scatter, } S \\
\text { (thickness in } \\
\text { microns) }\end{array}$ \\
\hline
\end{tabular}

\begin{tabular}{l|r|r}
\hline \multicolumn{3}{c}{ VITREOUS ENAMEL } \\
\hline 1 \\
\hline 4
\end{tabular}

PAPER

\begin{tabular}{|c|c|c|}
\hline Rag writing ................. & 0.89 & 0.032 \\
\hline Sulphite writing & .81 & .026 \\
\hline 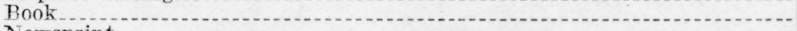 & .83 & .041 \\
\hline Newsprint & .61 & .030 \\
\hline
\end{tabular}

DENTAL SILICATE CEMENT

\begin{tabular}{|c|c|c|}
\hline $\begin{array}{l}F \quad \text { (white) } \\
D \text { (light yellow) } \\
D \text { (light yellowish gray) } \\
K \text { (white) } \\
K \text { (dark gray) }\end{array}$ & $\begin{array}{r}0.76 \\
.50 \\
.40 \\
.59 \\
.16\end{array}$ & $\begin{array}{r}0.0006 \\
.0004 \\
.0004 \\
.0002 \\
.0002\end{array}$ \\
\hline
\end{tabular}

The methods and graphical aids presented herein serve not only for the derivation of the fundamental constants of a light-scattering material according to the Kubelka-Munk theory but also for the reverse derivation, that of the reflectance and opacity of any thickness of the material of known constants. They also indicate the effect on reflectance and opacity produced by adding nonscattering dye or pigment. By means of these methods and graphical aids it has been found convenient to apply the Kubelka-Munk theory, and this theory has been useful in research as well as in the specification of lightscattering materials.

Washington, July 2, 1937. 